\title{
Acceso a la universidad y equidad
}

\author{
Vera Sacristán Adinolfi \\ Universitat Politécnica de Catalunya. Departament de Matemàtiques
}

Rebut: 13/07/2017 Acceptat: 15/09/2017

\section{Resumen}

El sistema universitario ha ido evolucionando progresivamente hacia una configuración más amplia y equitativa, pero todavía subsisten una serie de desigualdades manifiestas. Además de analizar el importante crecimiento del acceso a la universidad en las últimas décadas, en el presente artículo se analiza si este crecimiento se ha producido o no de forma socialmente equitativa. Por un lado, se aborda si las desigualdades económicas y culturales de partida inciden no sólo en el acceso a la universidad, sino también en la elección de los estudios y en las condiciones de vida estudiantil de los universitarios. Asimismo, al examinar la igualdad de oportunidades en el acceso, el estudio considera también la cuestión desde el punto de vista de la igualdad de género, así como el efecto del incremento sustancial de los precios de las matrículas universitarias, entre otros aspectos. Estas desigualdades en el sistema educativo, pueden comportar no solo efectos en la equidad, sino un mal aprovechamiento del talento de una sociedad.

Palabras clave: Equidad, igualdad de oportunidades, género, matrículas universitarias

\begin{abstract}
The university system has progressively evolved towards a wider and more equitable configuration, but a series of manifest inequalities still exist. In addition to analyzing the important growth of access to the university in recent decades, this article analyzes whether this growth has occurred or not in a socially equitable manner. On the one hand, it addresses whether the economic and cultural inequalities of departure affect not only the access to the university, but also in the choice of studies and the student's living conditions of the university students. Likewise, when examining equal opportunities in access, the study also considers the issue from the point of view of gender equality, as well as the effect of the substantial increase in university tuition fees, among other aspects. These inequalities in the education system may not only have an effect on equity, but a misuse of the talent of a society.
\end{abstract}

Key words: Equity, equal opportunities, gender, university enrollment 


\section{Introducción. Expansión (y estancamiento) del sistema universitario español}

El curso 1969-1970, en España los estudiantes universitarios no alcanzaban los 350.000 (Pérez Díaz y Rodríguez, 2001). Cuarenta y siete años más tarde, se han más que cuadruplicado, y los datos provisionales del curso 2016-2017 apuntan a un total aproximado de 1.490.000.

La evolución del número de estudiantes, ilustrada en el Gráfico 1, muestra una clara tendencia creciente hasta el curso 1999-2000, cuando se alcanza la cifra de 1.589 .166 estudiantes universitarios. Esta cifra se reduce hasta el curso 2007-2008, probablemente por un efecto combinado de caída demográfica (que, sin embargo, había comenzado varios años antes) y de bonanza económica. La crisis que se pone de manifiesto en el año 2008 invierte la tendencia y, pese a que la demografía sigue cayendo, la matrícula universitaria vuelve a crecer fuertemente. Este incremento abrupto se estanca también abruptamente el curso 2012-2013, y desde entonces desciende lentamente el número de estudiantes universitarios en España.

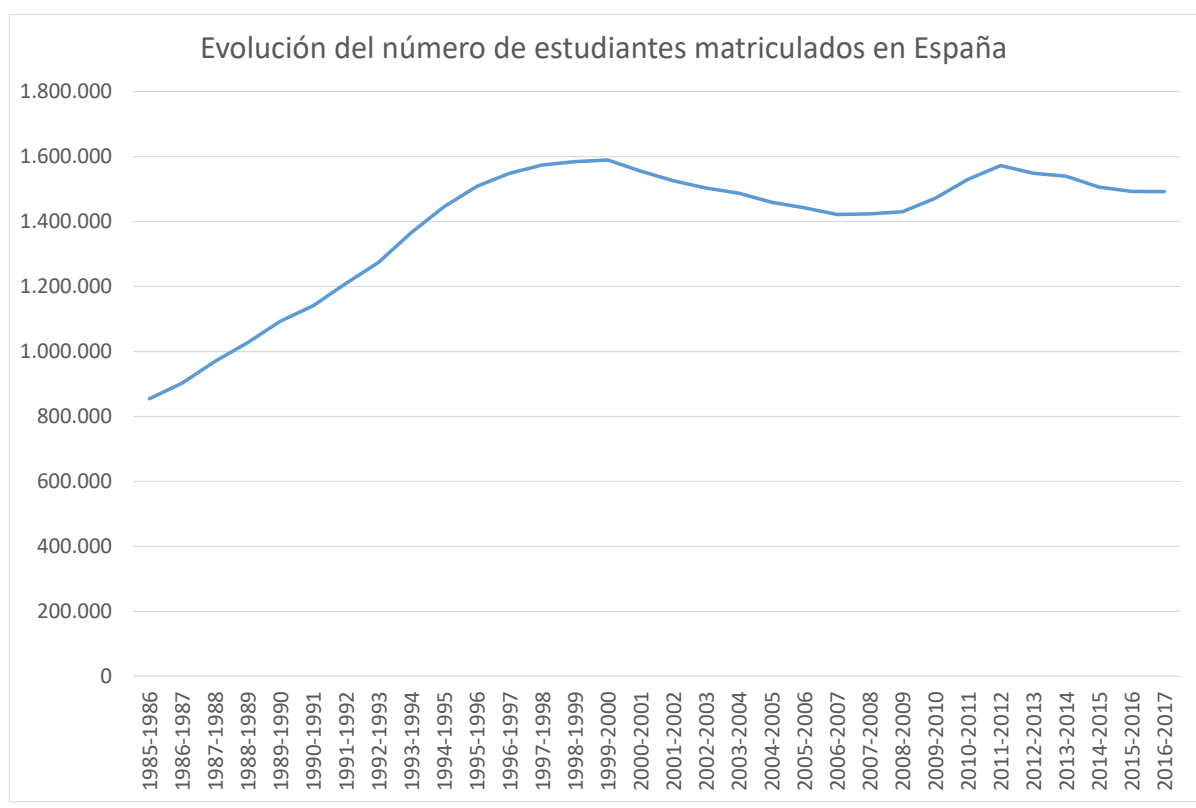

Gráfico 1. Fuente: elaboración propia a partir de MECyD, 2017 a.

Para comprender el alcance de estos datos, conviene ponerlos en relación con los datos demográficos. El curso 1969-70, la población joven (de entre 18 y 24 años de edad) matriculada en las universidades españolas era de poco más del 10\% (Pérez Díaz y Rodríguez, 2001). Se trataba de una universidad muy elitista en un país con un nivel educativo muy bajo. Diez años después del final de la dictadura, esta tasa casi se había duplicado y alcanzaba el 19\%. El Gráfico 2 muestra la evolución, desde entonces, del número de estudiantes universitarios (curva azul) a la par que la de la población en edad universitaria, esto es, de entre 18 y 24 años de edad (curva anaranjada). Ambas curvas se refieren a la escala situada a la izquierda del gráfico. Asimismo, el gráfico muestra la tasa de escolarización universitaria, esto es, el porcentaje de jóvenes que cursan estudios universitarios (curva gris). La escala de esta curva se encuentra situada a la derecha del gráfico. 


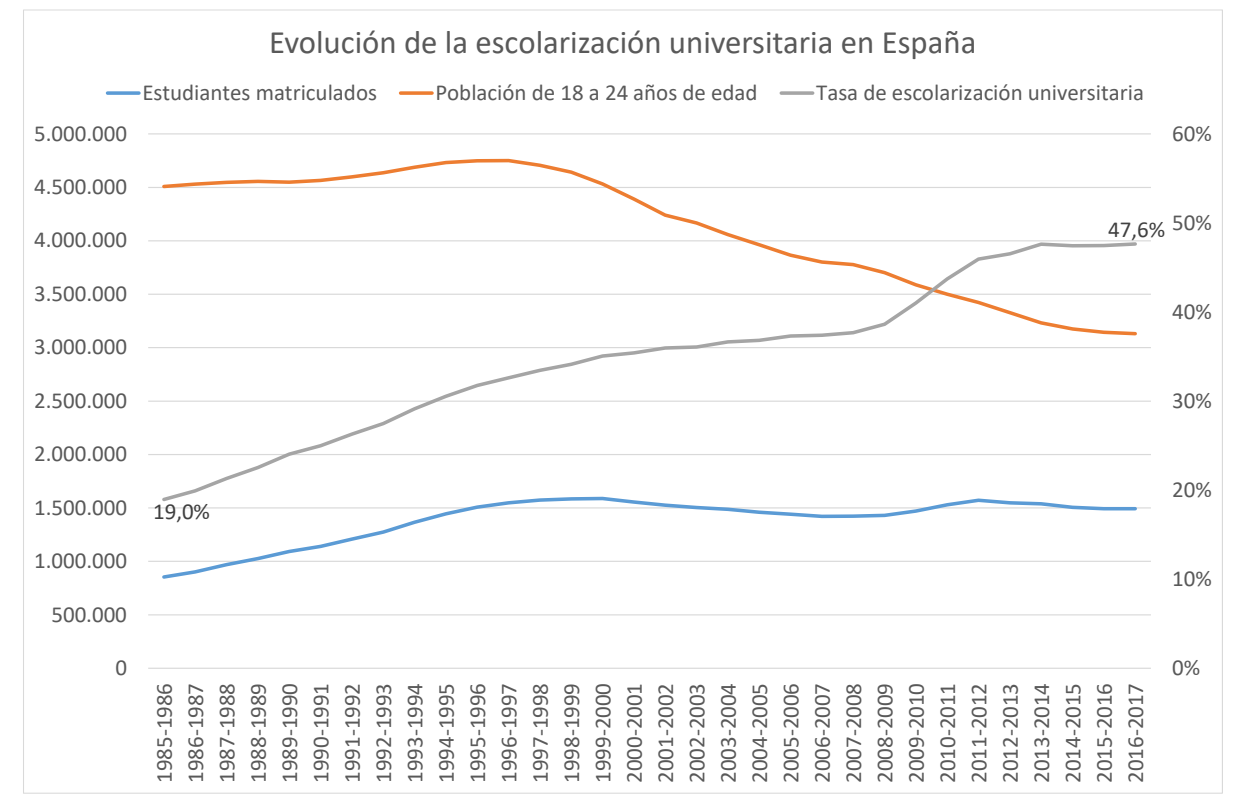

Gráfico 2. Fuente: elaboración propia a partir de INE (2017a) y MECyD (2017a).

Obsérvese que continuó manteniéndose un incremento constante del acceso de la población joven a los estudios universitarios hasta el curso 1999-2000. La caída antes mencionada en el número total de estudiantes matriculados del período 1999-2000 a 2007-2008 consistió, en realidad, en una ralentización del crecimiento de la tasa de escolarización universitaria de la población joven. El gráfico confirma, asimismo, que la crisis económica manifestada en 2008 produjo una gran aceleración del acceso de los jóvenes a la universidad. Desde el curso 20132014, dicha tasa puede considerarse estabilizada alrededor del 47,5\%. Esta fecha coincide con dos hechos que pueden explicar el fenómeno: el incremento substancial de los precios universitarios el curso 2012-2013 y el inicio de una gradual disminución de la tasa de paro de los jóvenes de entre 16 y 19 años (del 75,5\% del último trimestre de 2013 al 58,7\% del primer trimestre de 2017).

En los últimos años se han introducido grandes cambios en la estructura de los estudios universitarios en España. Además del ya mencionado incremento de los precios de matrícula, se han producido la distinción entre grados y másteres universitarios y la modificación de la duración de los estudios. Estos dos últimos elementos podrían introducir distorsiones en el cálculo del número total de estudiantes matriculados. Conviene pues, contrastar las hipótesis anteriores mediante el análisis de los datos de acceso a la universidad. El Gráfico 3 muestra la evolución del número de estudiantes que aprueban las pruebas de acceso a la universidad (curva azul), y la del número de jóvenes de 18 años de edad (curva naranja), ambas relativas a la escala situada a la izquierda del gráfico. Asimismo, el gráfico muestra la evolución de la tasa de acceso (curva gris), relativa a los porcentajes indicados en la escala situada a la derecha. 


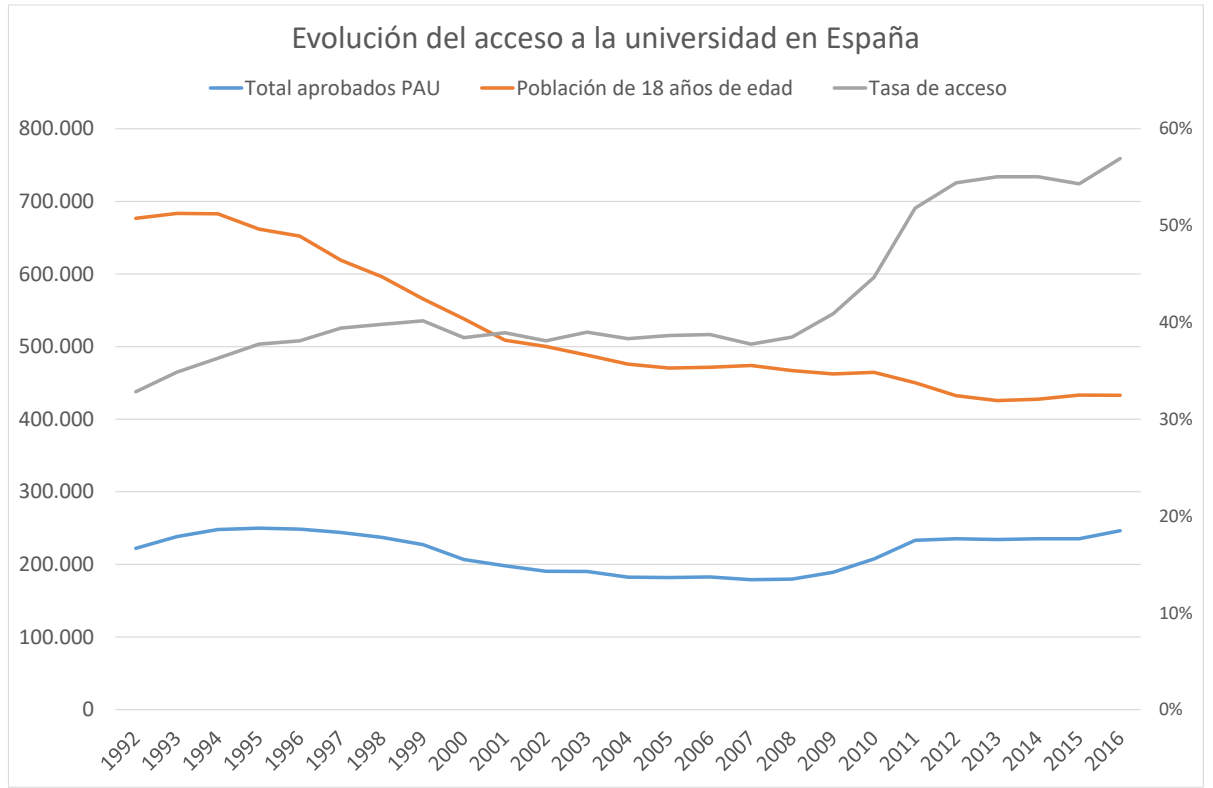

Gráfico 3. Fuente: elaboración propia a partir de INE (2017a) y MECyD (2016a).

De nuevo se observa la misma evolución: un período de crecimiento constante hasta 1999, una fase de estancamiento entre 1999 y 2007, un crecimiento muy fuerte entre 2008 y 2012, y una nueva fase de estancamiento entre 2013 y 2015. En el próximo futuro habrá que comprobar si se mantiene el crecimiento detectado en 2016, aunque bien podría tratarse de algún error en datos recientes y aún provisionales.

En conclusión, podemos afirmar que en las últimas décadas España ha asistido a un fenómeno histórico de expansión del acceso de los jóvenes a los estudios universitarios. También puede considerarse histórico el impacto de la crisis sobre el número de estudiantes universitarios. El análisis del estancamiento producido a partir del año 2013 requerirá un poco más de perspectiva, pero a día de hoy, cuatro años más tarde, se presenta como un elemento inquietante.

El proyecto "Europa 2020" de la Unión Europea marca como objetivo una tasa del $40 \%$ de la población de entre 30 y 34 años de edad con estudios universitarios. España, que ya la ha alcanzado (40,9\% en 2007), declara como objetivo el 44\%. En 2014, último años con datos publicados, era del 42,3\% (MECyD, 2016c).

\section{La universidad como ascensor social}

La expansión del sistema universitario español y el acceso a los estudios universitarios de un porcentaje más amplio de la población podría hacer creer que la universidad ha dejado de ejercer el papel de ascensor social común a todo el sistema educativo. De hecho, en la sociedad española o, al menos, en sus medios de comunicación de masas, frecuentemente parece persistir la idea de la universidad como fábrica de parados o, en una versión menos radical, de la universidad como causa de sobrecualificación de nuestra población joven. En tiempos de crisis económica, se ha venido a añadir el fenómeno de la emigración del talento joven, que parece rematar la idea de que estudiar no coadyuva a la promoción social. 
Sin embargo, tal como muestran infinidad de estudios, "la educación (1) aumenta las probabilidades de ascender a posiciones sociales altas; (2) merma las de descender en la escala social; y (3) reduce el riesgo de caer en el desempleo" (Requena, 2016).

En primer lugar, los datos muestran que, efectivamente, el desempleo no se distribuye por igual entre los distintos niveles educativos. Los datos de la Encuesta de Población Activa, ilustrados en el Gráfico 4, son muy claros al respecto: el nivel educativo y el riesgo de desempleo son inversamente proporcionales. Cuanto mayor es el nivel de estudios alcanzado, menor es la probabilidad de caer en el desempleo. Las diferencias, además, se agudizan durante los períodos de crisis económica y aumento del paro. Comparativamente con el resto de niveles educativos, la idea de la universidad como fábrica de parados no es más que un falso mito.

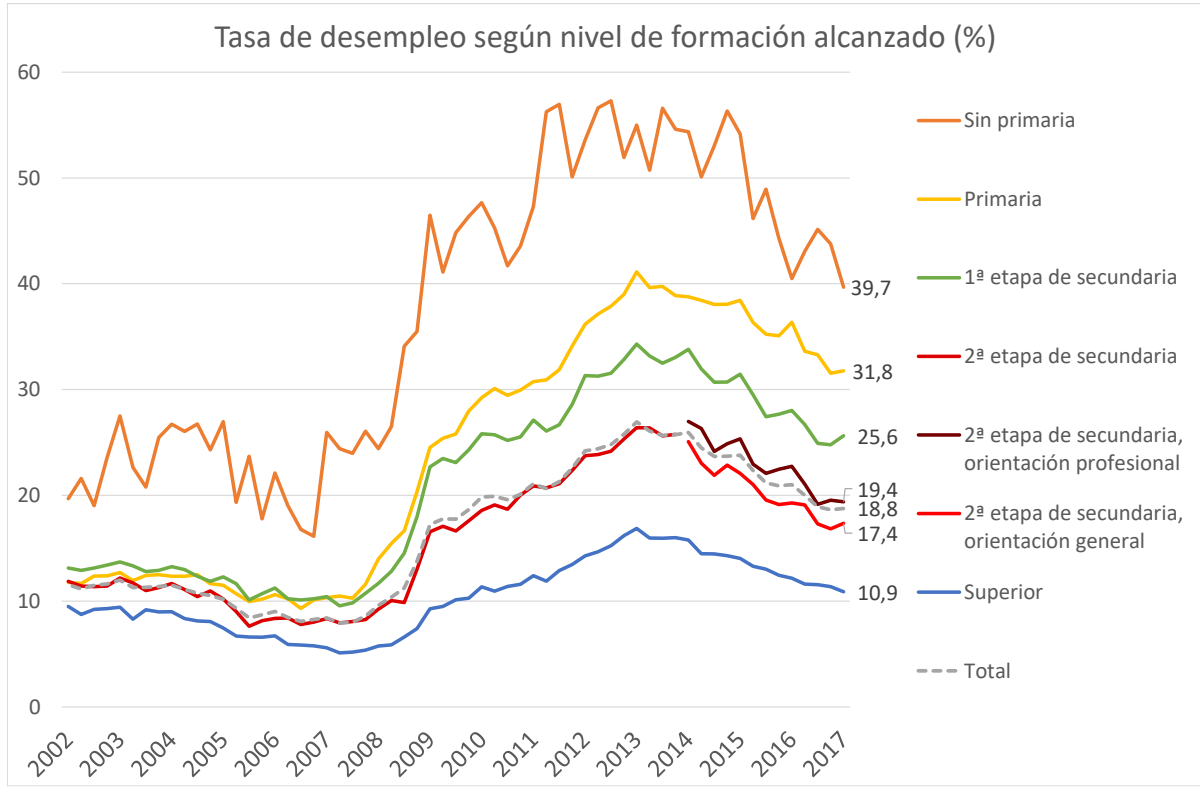

Gráfico 4. Fuente: elaboración propia a partir de INE (2017b) e INE (2017c).

Sin embargo, hay que tener presente que en la actualidad en España también es elevada la tasa de paro de las personas con titulación universitaria. Y lo es también comparativamente con los países de nuestro entorno. Concretamente, de acuerdo con los datos más recientes publicados por la OCDE, en 2015 la tasa de desempleo de los titulados universitarios de entre 25 y 64 años de edad era en España del 12,4\% (sólo superada por la tasa de Grecia de entre los 37 países analizados) frente al 4,6\% de media de la OCDE (OCDE, 2015). Un año más tarde, en 2016, la tasa era del 10,9\% en España, frente al 4,7\% de la UE y el 5,8\% de la zona euro (Eurostat, 2016).

En cuanto a la sobrecualificación de los titulados universitarios o, más en general, a las ocupaciones de aquellos de ellos que trabajan, Requena (2016) muestra con rotundidad (véase el Gráfico 5, que reproducimos de la fuente) que "los titulados superiores registran tasas más altas -es decir, tienen más probabilidades- de acceso a las clases profesionales y directivas que los que carecen de título superior" y ello con independencia de la clase social de origen. Más concretamente, "entre los que proceden de los orígenes sociales más bajos, los universitarios tienen catorce veces más probabilidades de acceder a las ocupaciones profesionales y directivas que quienes no completaron la educación secundaria. Los universitarios hijos de padres de clases 
intermedias tienen tres veces más probabilidades de convertirse en directivos o profesionales que quienes no llegaron a secundaria. $Y$ aquellos con estudios universitarios procedentes de familias con padres profesionales o directivos tienen el doble de probabilidades de mantenerse en su clase de origen que los que tienen un nivel inferior a secundaria". "En otras palabras", concluye Requena, "los títulos educativos conceden una gran ventaja para la movilidad ascendente en todas las clases sociales; además, la ventaja que otorgan es mayor cuanto más baja es la posición social de partida".

\section{Gráfico 1. Probabilidad de acceder a las clases de profesionales y directivos según clase de origen y nivel educativo}

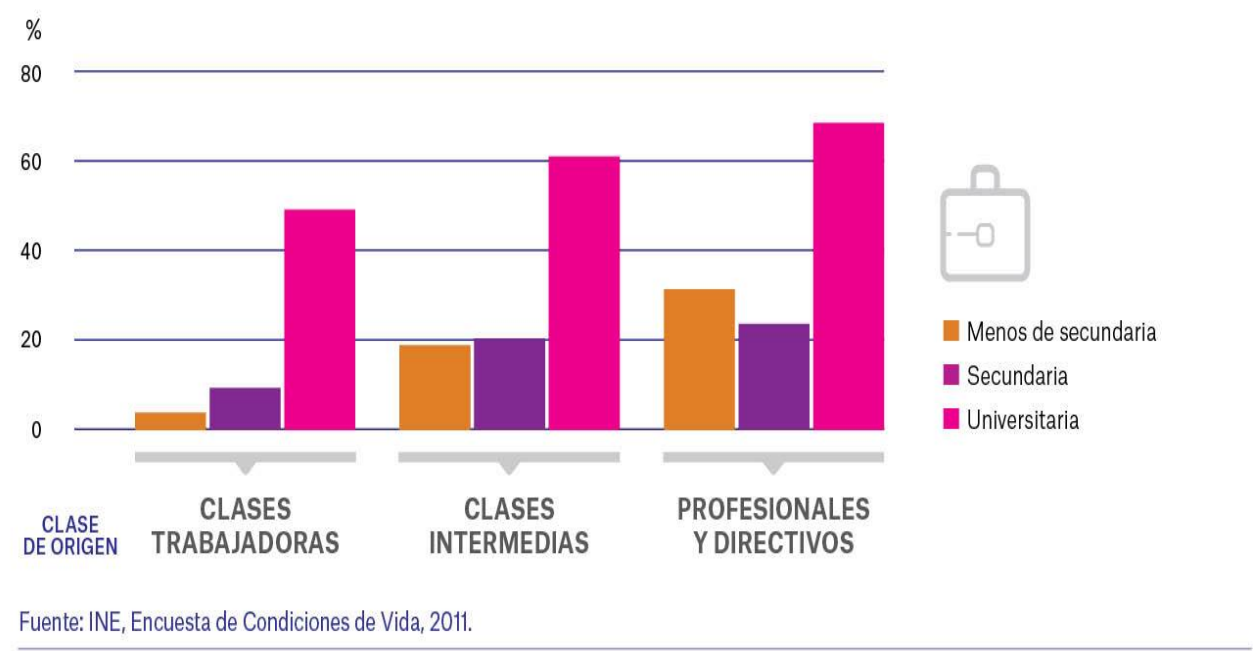

Gráfico 5. Fuente: Requena (2016).

Todo esto no quiere decir que las perspectivas de movilidad se hayan desvinculado del origen social ya que, a igualdad de condiciones educativas, los hijos de los profesionales y directivos tienen 2,8 veces más probabilidades de llegar a ser profesionales y directivos que los hijos de trabajadores y 1,4 veces más que los hijos de las clases intermedias (Requena, 2016).

\section{La composición del estudiantado, sesgada socialmente}

De lo expuesto hasta aquí se deduce la importancia de conocer si el importante crecimiento del acceso a la universidad en de las últimas décadas se ha producido o no de forma socialmente equitativa.

Cabe recordar que la universidad de los años 70 tenía una configuración definitivamente elitista. Los datos del Informe FOESSA de 1970, indicaban que los hijos de padres de las cuatro categorías profesionales más elevadas (cuadros superiores y profesionales liberales; cuadros medios; empresarios con asalariados de la industria y de los servicios; y empresarios agrarios con asalariados) representaban el $57,2 \%$ del total de los estudiantes universitarios, mientras que dichos padres suponían sólo el $12 \%$ de la población activa masculina. Los procedentes de las cinco categorías profesionales más bajas (obreros cualificados; personal cualificado de la agricultura; agricultores sin asalariados; obreros sin cualificar; y jornaleros del campo) agrupaban 
únicamente al 13,5\% del estudiantado de este escalón educativo, mientras que sus padres representaban el $64,5 \%$ de la población activa masculina. En un extremo se situaban los cuadros superiores y profesionales liberales, que formaban el 3,3\% de la población activa masculina, y cuyos hijos llegaban a representar el 31,9\% del total del estudiantado universitario. En el otro, los jornaleros del campo, que suponían el $10 \%$ de la población activa masculina, mientras que sus hijos no llegaban a alcanzar el 1\% de los universitarios de entonces (Barañano, Finkel y Rodríguez, 2011).

Desde entonces la composición social del estudiantado universitario ha evolucionado mucho. El Gráfico 6 muestra la ocupación del padre de los estudiantes universitarios como indicador del origen social de éstos, a partir de los datos de la última encuesta a nivel europeo en la que España participó, Eurostudent IV. El gráfico permite comparar la distribución resultante con la de la población de varones de entre 40 y 60 años de edad, es decir, el conjunto de padres potenciales. Los datos corresponden al año 2010.

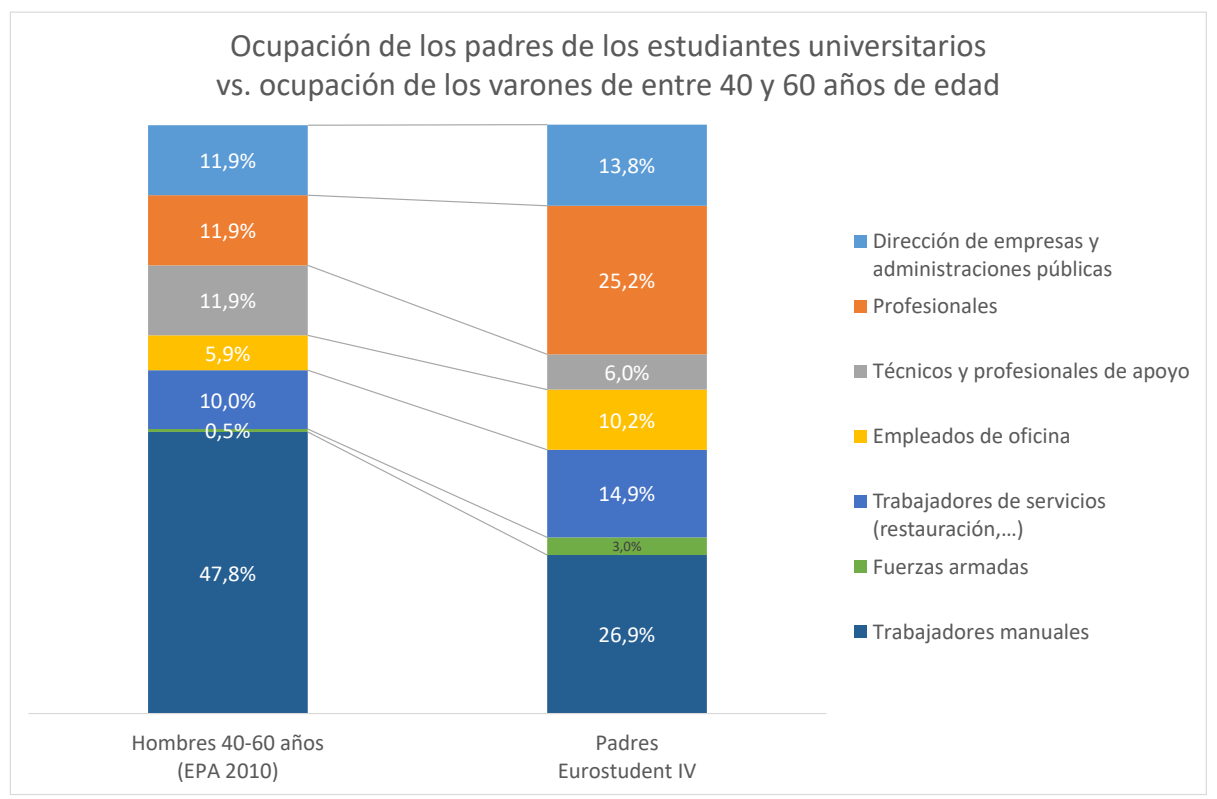

Gráfico 6. Fuente: elaboración propia a partir de Barañano, Finkel y Rodríguez (2011).

Salta a la vista que las clases más bajas (trabajadores manuales, y técnicos y profesionales de apoyo) siguen estando subrepresentadas en el conjunto de los estudiantes universitarios, aunque en mucho menor medida que en los años 70 . Sin embargo, el caso de los trabajadores manuales sigue siendo especialmente grave, ya que representan casi el $48 \%$ de la población activa masculina de entre 40 y 60 años de edad en España, pero sus hijos representan algo menos del $27 \%$ del estudiantado universitario. En sentido inverso, el grupo de profesionales es el más sobrerrepresentado (más del doble) entre los padres de los universitarios.

En conclusión, la distancia entre el peso de los trabajadores manuales entre los padres de los estudiantes universitarios y el que tienen en el conjunto de la población masculina de entre 40 y 60 años de edad ha descendido radicalmente desde los años 70, y lo ha hecho hasta muy recientemente por lo menos. Concretamente, entre 2007 -año de la anterior oleada de encuestas, Eurostudent III- y 2010, descendió casi 10 puntos, debido a la combinación de dos circunstancias: el incremento de la presencia de estudiantes universitarios cuyos padres son trabajadores 
manuales -un 26,9\% en 2011 frente a un 20,2\% en 2007-y el descenso de estos últimos en el conjunto de la población masculina ocupada -50,8\% en 2007 y 47,8\% en 2010- (Barañano, Finkel y Rodríguez, 2011).

La Tabla 1 resume la evolución entre 2007 y 2010, de acuerdo con los datos publicados por Barañano, Finkel y Rodríguez (2011). En la tabla, el valor 1 en cada fila indicaría un sistema universitario en el que la composición del alumnado reflejara perfectamente la composición de la sociedad, valores superiores a 1 indican sobrerrepresentación, valores inferiores a 1 indican infrarrepresentación.

Desgraciadamente, España ha dejado de participar en las encuestas Eurostudent, que han visto ya dos nuevas oleadas (Eurostudent $\mathrm{V}$ y VI). Ello nos priva de datos que nos permitan hacer el seguimiento de esta relevante cuestión social.

\begin{tabular}{|c|c|c|c|}
\hline & \multirow[t]{2}{*}{ Tabla 1} & \multicolumn{2}{|c|}{$\begin{array}{l}\text { padres de estudiantes / } \\
\text { varones de } 40 \text { a } 60 \text { años }\end{array}$} \\
\hline & & 2007 & 2010 \\
\hline \multirow{7}{*}{$\overline{0}$} & Dirección de empresas y administraciones públicas & 1,9 & 1,2 \\
\hline & Profesionales & 1,7 & 2,1 \\
\hline & Técnicos y profesionales de apoyo & 1,0 & 0,5 \\
\hline & Empleados de oficina & 2,1 & 1,7 \\
\hline & Trabajadores de servicios (restauración,....) & 1,7 & 1,5 \\
\hline & Fuerzas armadas & 1,5 & 6,0 \\
\hline & Trabajadores manuales & 0,4 & 0,6 \\
\hline
\end{tabular}

Tabla 1. Fuente: elaboración propia a partir de Barañano, Finkel y Rodríguez (2011).

Más que las diferencias estrictamente económicas, son las diferencias de índole sociocultural las que inciden de forma más significativa sobre las trayectorias educativas (Calero y Choi, 2012). También en este sentido, la evolución de la universidad española ha sido muy notable, tal como resume la Tabla 2, en la que se muestra el porcentaje de población que alcanza nivel educativo terciario (ISCED 5) en función del nivel máximo de estudios alcanzado por sus progenitores. Calero y Choi (2012) concluyen que "el sistema educativo español se ha convertido en más «móvil» desde el punto de vista de las posiciones educativas intergeneracionales". Esta mayor movilidad es un rasgo común a todos los sistemas educativos europeos. Sin embargo, como indican los autores, conviene resaltar "en primer lugar, que el punto de partida de España corresponde, comparativamente, a una posición de reducida movilidad al inicio del periodo analizado. En segundo lugar, la movilidad que se alcanza hacia el final del periodo es todavía inferior a la de otros países europeos como Austria, Bélgica, Dinamarca, Finlandia, Francia, Holanda, Noruega o Suecia". 


\begin{tabular}{|c|c|c|c|}
\hline & \multirow{2}{*}{ Tabla 2} & \multicolumn{2}{|c|}{$\begin{array}{c}\text { Porcentaje de población con } \\
\text { estudios terciarios }\end{array}$} \\
\hline & & $\begin{array}{c}\text { Nacidos entre } \\
1940 \text { y } 1945\end{array}$ & $\begin{array}{c}\text { Nacidos entre } \\
1970 \text { y } 1975\end{array}$ \\
\hline \multirow{4}{*}{ 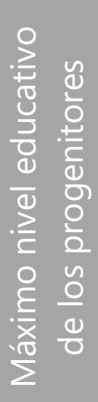 } & $\begin{array}{l}\text { Terciaria } \\
\text { (ISCED 5) }\end{array}$ & $58,2 \%$ & $71,3 \%$ \\
\hline & $\begin{array}{l}\text { Secundaria post-obligatoria } \\
\text { (ISCED 3) }\end{array}$ & $35,4 \%$ & $52,9 \%$ \\
\hline & $\begin{array}{l}\text { Secundaria obligatoria } \\
\text { (ISCED 2) }\end{array}$ & $16,1 \%$ & $40,1 \%$ \\
\hline & $\begin{array}{l}\text { Hasta enseñanza primaria } \\
\text { (ISCED 0-1) }\end{array}$ & $7,4 \%$ & $27,3 \%$ \\
\hline
\end{tabular}

Tabala 2. Fuente: Elaboración propia a partir de Calero y Choi (2012).

Una representación gráfica de la clara sobrerrepresentación de los padres de estudiantes universitarios con educación superior, en comparación con el peso de los varones con ese nivel educativo en el total de la población masculina de 40 a 60 años de edad puede verse en el Gráfico 7. A pesar del aumento en 7 puntos porcentuales de la presencia de estudiantes cuyo padre tiene un nivel educativo bajo (hasta la primera etapa de la educación secundaria), producido en el período de tan sólo tres años que va de Eurostudent III a Eurostudent IV, en 2010 el porcentaje de padres de hijos universitarios con este nivel educativo (35,5\%) sigue siendo claramente inferior al que arrojan los varones del mismo nivel de estudios sobre el conjunto de la población masculina de 40 a 60 años (52,4\%) (Barañano, Finkel y Rodríguez, 2011).

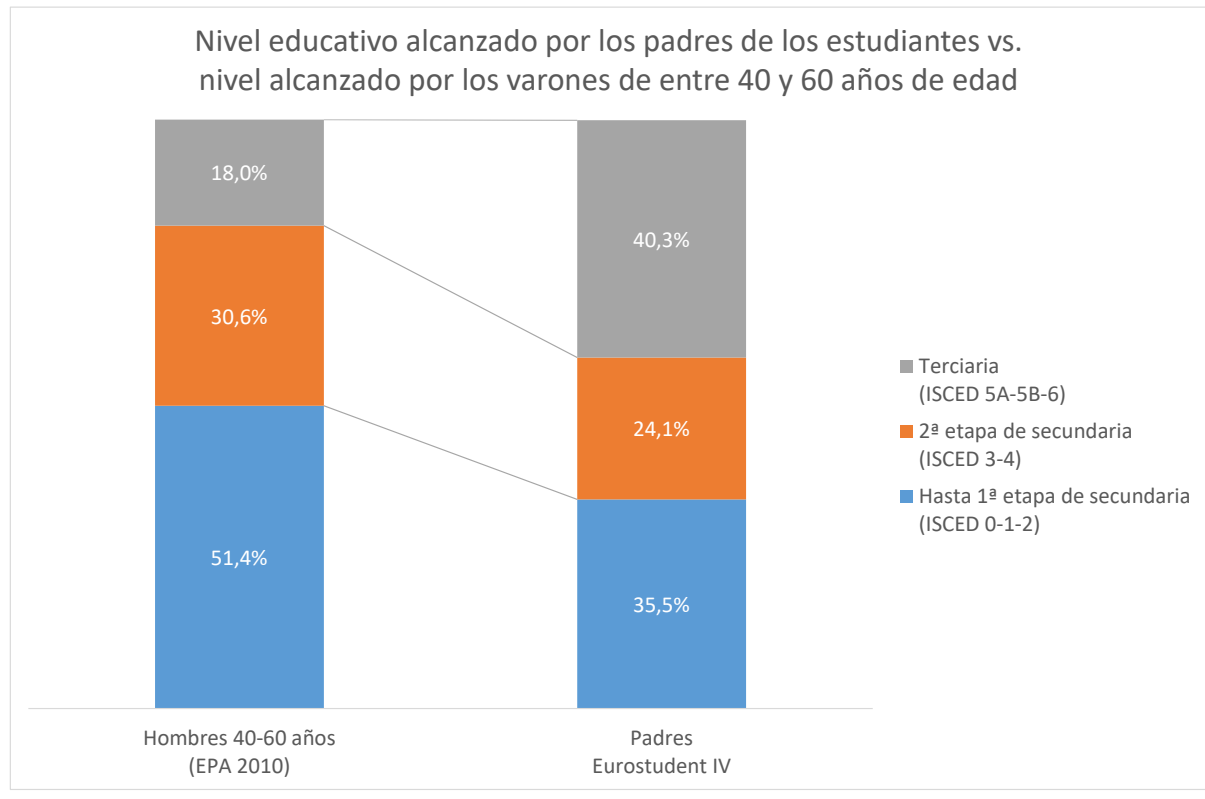

Gráfico 7. Fuente: Elaboración propia a partir de Barañano, Finkel y Rodríguez (2011).

Los mismos datos pueden analizarse en términos de la probabilidad de que los hijos y las hijas de personas con uno $u$ otro nivel educativo alcancen la universidad. La Tabla 3 muestra estas probabilidades 0 , más precisamente, las ratios entre los padres de universitarios y la población 
masculina de entre 40 y 60 años de edad de los diversos niveles educativos. De nuevo, el valor 1 correspondería a un sistema universitario en el que la composición del alumnado reflejara perfectamente la composición de la sociedad. Puesto que la ratio para niveles educativos altos es muy superior a 1 , se deduce que nuestro sistema universitario sobrerrepresenta a quienes proceden de padres con educación superior -con una ligera disminución en 2010 respecto de 2007-, así como infrarrepresenta a los estudiantes provenientes de los niveles educativos más bajos -también de manera menos acentuada en 2010 que en 2007- (Barañano, Finkel y Rodríguez, 2011). Como actualización de estas ratios, disponemos de las encuestas del proyecto Via Universitaria, llevadas a cabo por las universidades de habla catalana, que confirman la tendencia hasta aquí expresada, y también del análisis de Troiano, Torrents y Sànchez-Gelabert (2016) para el caso de Cataluña.

\begin{tabular}{|c|c|c|c|c|}
\hline \multicolumn{1}{|c|}{ Tabla 3 } & \multicolumn{3}{c|}{ padres de estudiantes / varones de 40 a 60 años } \\
\hline & 2007 & 2010 & 2016 (Cataluña) \\
\hline & 2,3 & 2,2 & 1,8 \\
\hline & 1,1 & 0,8 & 0,8 \\
\hline
\end{tabular}

Tabla 3. Fuente: elaboración propia a partir de Barañano, Finkel y Rodríguez (2011) y Troiano, Torrents y SànchezGelabert (2016).

En resumen, pues, a pesar de su progresiva democratización, el acceso a los estudios universitarios en España sigue presentando de una desigualdad social manifiesta. La posición socioeconómica de las familias de los jóvenes condiciona su acceso a la enseñanza superior, y la condiciona quizás aún más claramente su situación sociocultural.

\section{Influencia del origen sociocultural en el qué y el cómo de los estudios universitarios}

En este contexto, es relevante entender si las desigualdades socioeconómicas y culturales de partida inciden no sólo en el acceso a la universidad, sino también en la elección de los estudios y en las condiciones de vida estudiantil de los universitarios.

Los trabajos realizados indican que el origen socioeconómico y sociocultural de los estudiantes condiciona la elección de los estudios a cursar y determina diferencias en cuanto a las condiciones del estudio. Troiano y Elias (2014), en base a una encuesta llevada a cabo a 857 estudiantes de las cuatro universidades del área metropolitana de Barcelona (UAB, UB, UPF y UPC) en 2013, concluyen que "por un lado, los estudiantes de clase trabajadora ven los estudios como un privilegio y una carga para sus familias. Su motivación principal para estudiar en la universidad es mejorar su situación económica y, por lo tanto, buscan maximizar el beneficio a corto plazo: estudios de ciclo corto, próximos geográficamente y con salidas laborales claras y rápidas (motivación instrumental). Además, prefieren carreras en las que el ambiente social y cultural les es más próximo (menos elitistas económica o académicamente). Viendo los estudios como una inversión, sufren más angustia por la posibilidad de fracasar y minimizan el riesgo escogiendo carreras con una percepción social de menor dificultad académica. En cambio, los hijos de clases 
medias y altas ven la formación universitaria como un derecho y parte de su estilo de vida, con el apoyo de sus familias. Para los estudiantes de estas clases sociales es menos preocupante el futuro laboral, y tienen más libertad para escoger sus estudios (motivación expresiva)".

Los datos que confirman estas tesis son abundantes.

\section{1 Áreas de estudio y clase social}

En cuanto a la elección de la temática objeto de los estudios, Barañano, Finkel y Rodríguez (2011) encuentran que las distintas áreas de conocimiento están asociadas a la situación laboral del padre: "los estudiantes de Humanidades y Ciencias Sociales tienen padres con tasas de ocupación a tiempo completo del $54 \%$ y $59 \%$ respectivamente, más bajas, en consecuencia, que las correspondientes a los padres de alumnos de carreras Técnicas (64\%), de Ciencias de la Salud (68\%) y de Ciencias (72\%). Esta situación se invierte en el caso de los padres inactivos." Según estos autores, las diferencias respecto de la clase social (en términos de la ocupación del padre, cuando éste tiene una ocupación) "no son muy abultadas, aunque sigue observándose una mayor presencia de padres y madres trabajadores manuales entre los estudiantes de Ciencias Sociales, de Humanidades y de enseñanzas Técnicas, frente a los que cursan especialidades de Ciencias de la Salud, y sobre todo, titulaciones del área de Ciencias".

\subsection{Las salidas profesionales, como criterio de elección de los estudios}

La elección de estudios en función de sus salidas profesionales también es diferente según la clase social de origen, tal como ilustra la Tabla 4.

\begin{tabular}{|l|c|c|}
\hline \multirow{2}{*}{ Tabla 4} & \multicolumn{2}{c|}{ Qué motiva la elección de la carrera (Barcelona, 2010) } \\
\cline { 2 - 3 } & Ocupación futura & Interés académico en los contenidos \\
\hline Clases media y alta & $35 \%$ & $41,5 \%$ \\
\hline Clase trabajadora & $44 \%$ & $50 \%$ \\
\hline
\end{tabular}

Troiano, Torrents y Sànchez-Gelabert (2016), en su análisis de los datos de las universidades públicas catalanas, también observan que los estudiantes de origen educativo más bajo (la máxima titulación de cuyos padres es hasta estudios obligatorios) eligen en menor proporción titulaciones con ingresos esperados altos, esto es, estudios cuyos titulados obtienen, al cabo de tres años de haber obtenido la titulación, una media de ingresos por encima de la mediana (que varía según los resultados de cada promoción estudiada). Asimismo, estos estudiantes de origen educativo más bajo eligen titulaciones con inserción laboral más rápida (de 0 a 1 mes).

\subsection{La dificultad percibida, como criterio de elección de los estudios}

A través de encuestas se ha podido establecer que los estudiantes de clase trabajadora procuran minimizar el riesgo de fracaso en sus estudios universitarios por la vía de evitar escoger carreras percibidas como muy difíciles. Los datos en España confirman esta hipótesis en términos generales, pero con excepciones, que tienen que ver con las expectativas de éxito laboral. Así, por 
ejemplo, estos estudiantes no suelen elegir estudios de humanidades a pesar de su baja dificultad percibida, mientras eligen estudiar carreras de ingeniería, que suelen ser consideradas más difíciles. Así pues, todo parece indicar que, aunque el factor "dificultad" está presente en la elección de carrera, se ve modulado por la expectativa en cuanto a las salidas laborales.

\subsection{La duración, como criterio de elección de los estudios}

Mientras los estudios universitarios en España tuvieron duraciones distintas, los estudiantes de clase trabajadora se concentraban en estudios de 3 años de duración (diplomaturas, ingenierías técnicas y arquitectura técnica), que contaban en 2010 con un $45 \%$ de estudiantes cuyos padres tenían bajos niveles de estudios (49\% en el caso de las madres). En dichas carreras de ciclo corto, los hijos de padres con titulación universitaria superior representaban tan sólo el $13 \%$ de los estudiantes ( $8 \%$ en el caso de las madres) (Barañano, Finkel y Rodríguez, 2011). Troiano y Elias (2014) confirman esta clara tendencia.

Una vez desaparecida la distinción entre diplomaturas y licenciaturas, cabe preguntarse por la evolución de este criterio de elección de los estudios por parte de los jóvenes. Troiano, Torrents, y Sànchez-Gelabert (2016) han analizado los datos correspondientes a las universidades de Cataluña. Tras llevar a cabo una pormenorizada correlación entre (algunos de) los nuevos estudios de grado y las antiguas carreras de ciclo corto y de ciclo largo, observan que el cambio producido entre 2005 i el 2011 comportó una ampliación del porcentaje de estudiantes en grados que anteriormente eran de ciclo largo, y una reducción del porcentaje de estudiantes que escogen titulaciones que antes eran de ciclo corto (véase la Tabla 5). En este proceso de expansión de las titulaciones que previamente eran de ciclo largo, se constata que los estudiantes cuyos progenitores tienen estudios hasta obligatorios incrementan su participación en estudios que anteriormente eran de ciclo largo (2005: 49.3\%; 2011: 53.5\%) y lo mismo ocurre con los hijos de progenitores con estudios secundarios post-obligatorios (2005: 54.5\%; 2011: 58.6\%).

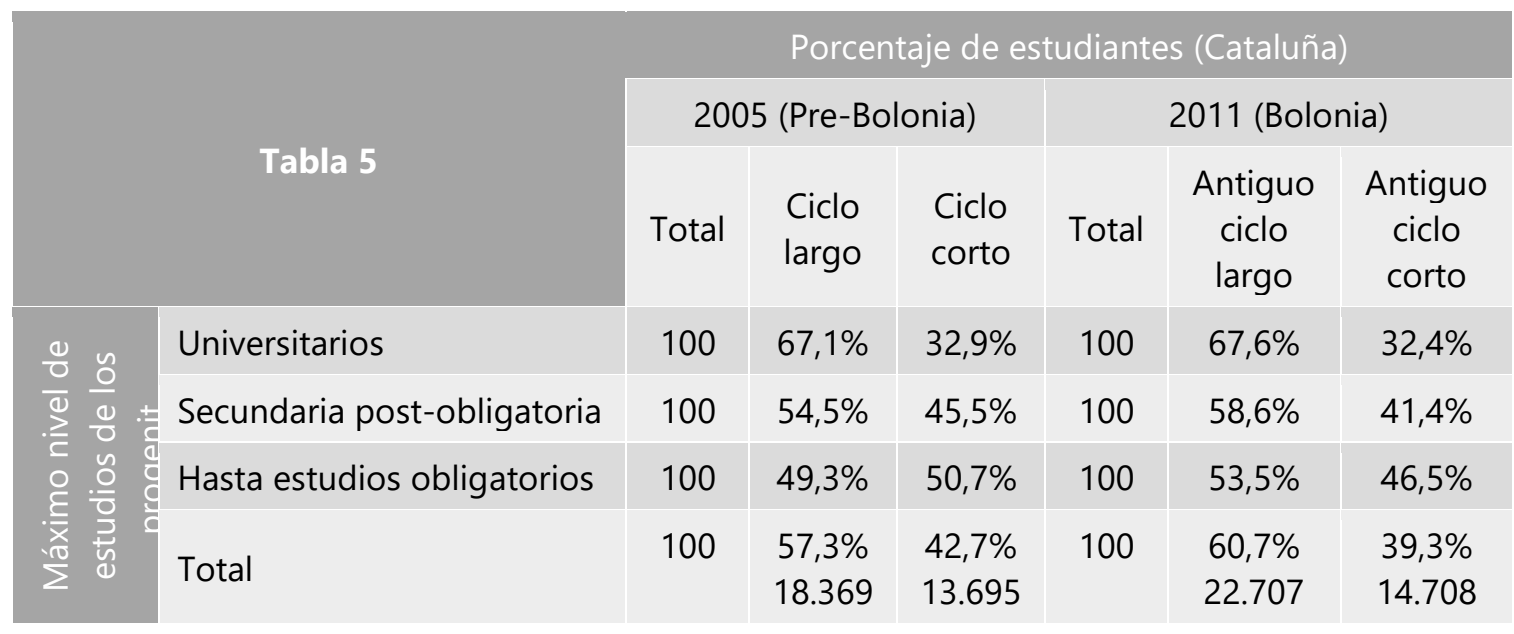

Tabla 5. Fuente: Troiano, Torrents, y Sànchez-Gelabert (2016).

Todo parece indicar, pues, que la repercusión de la desaparición de las titulaciones de ciclo corto no ha sido negativa para los estudiantes de orígenes más bajos, sino todo lo contrario: la eliminación del factor "duración de los estudios" ha favorecido el incremento de su presencia en estudios en los que previamente eran más minoritarios. 


\subsection{El efecto "compensación"}

El efecto compensación se refiere a la capacidad de las familias socialmente mejor situadas de contrarrestar de diversas maneras las insuficiencias académicas de sus hijos, y a su capacidad de hacerlos progresar a pesar de que obtengan resultados académicos más pobres.

Troiano, Torrents y Sànchez-Gelabert (2016) constatan que dicho efecto está presente no sólo en la decisión de emprender estudios universitarios, sino también en la elección de los estudios a cursar. El Gráfico 8 muestra la tasa de elección de estudios cuyos precios de matrícula son altos, en función del nivel de estudios de los progenitores y las notas obtenidas, para el año 2014 en Cataluña. En él se observa que los estudiantes con notas de acceso bajas eligen su carrera de forma similar, con independencia de su origen educativo, mientras que los que acceden a la universidad con notas altas eligen de forma distinta en función de su origen. Según los autores, los estudiantes de origen social bajo, a pesar de haber demostrado tener las mismas capacidades, perciben unas probabilidades de éxito inferiores y adoptan una estrategia de reducción del riesgo.

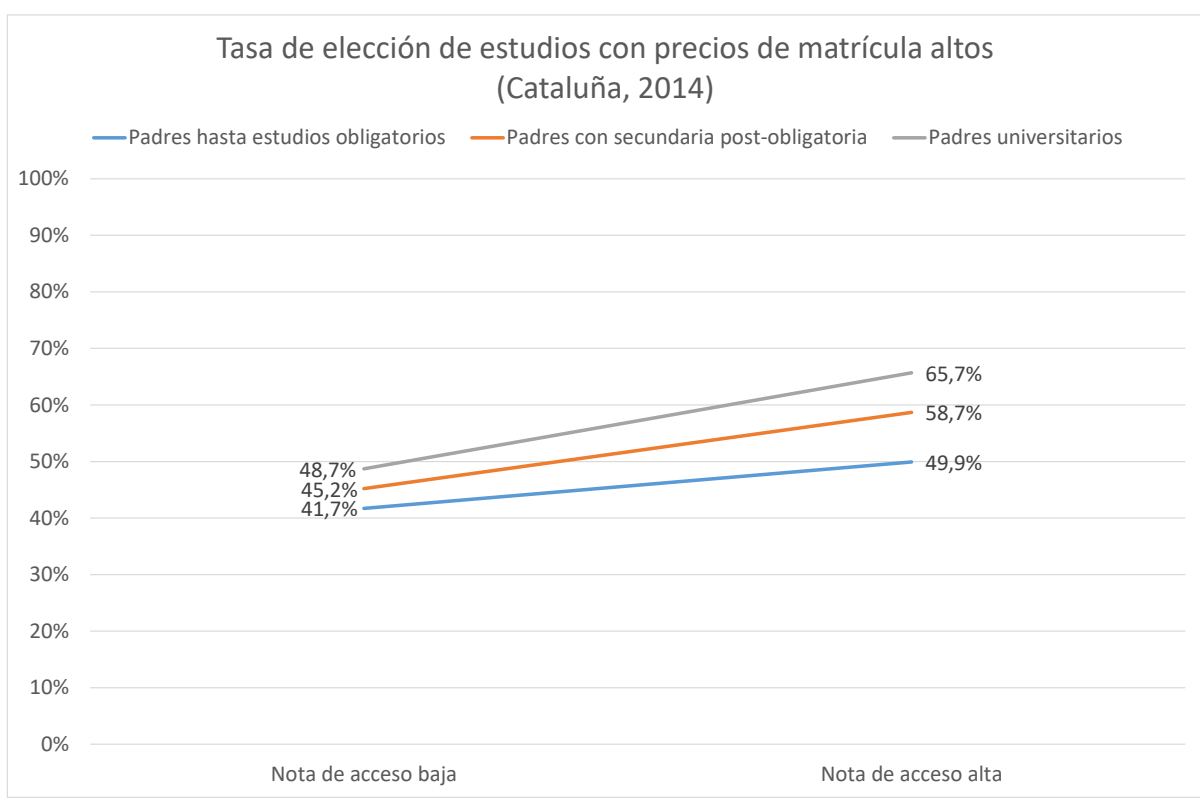

Gráfico 8. Fuente: Troiano, Torrents y Sànchez-Gelabert (2016).

\subsection{Condiciones de estudio}

Otro aspecto importante en el que interviene claramente el condicionante social es el de las condiciones del estudio. En primer lugar, abordamos la edad de acceso a los estudios universitarios. Barañano, Finkel y Rodríguez (2011) constatan que a mayor edad del estudiante (más de 30 años) menor es el porcentaje de padres ocupados a tiempo completo y mayor el de padres inactivos. Asimismo, se incrementa la proporción de padres con niveles educativos bajos y disminuyen aquellos con niveles educativos altos, y es más frecuente encontrar padres trabajadores manuales. Esto guarda relación con la mayor tendencia de estos jóvenes a cursar ciclos formativos. Sólo tras finalizarlos, algunos de ellos se plantean acceder a la universidad.

Los estudiantes que han tenido una transición directa a la universidad provienen, en mayor medida que los que han tenido una transición retrasada, de padres que trabajan a tiempo completo. Por otro lado, el porcentaje de padres y madres trabajadores manuales es más elevado 
entre aquellos que han experimentado una transición retrasada a la universidad (Barañano, Finkel y Rodríguez, 2011).

Se observa, además, que las ciencias sociales son las preferidas por personas con estudios previos y experiencia laboral, mientras que las ciencias naturales son un claro ejemplo de estudios vocacionales a los que el $92 \%$ de los estudiantes acceden directamente desde el bachillerato.

Otro factor muy importante a la hora de analizar las condiciones de estudio es la dedicación a éste. En su trabajo referido a las universidades públicas del área metropolitana de Barcelona, Troiano y Elias (2014) constatan que, a mayor presencia de estudiantes de clase trabajadora, mayor es el número de horas de trabajo declaradas: en carreras con un porcentaje alto de estudiantes de clase trabajadora, muchos compatibilizan estudio y trabajo, aunque no siempre esta compatibilización esté prevista y apoyada por la organización docente de las universidades. Como ejemplos, mencionan Enfermería, con un 50\% de estudiantes con trabajos de media jornada o más, e Ingeniería Técnica en Telecomunicaciones (37\%).

Los datos referidos al conjunto de España van en la misma dirección: "la intensidad de los estudios presenta una asociación positiva con el empleo a tiempo completo del padre, mientras que ocurre lo contrario con las horas de trabajo a la semana del estudiante", concluyen (Barañano, Finkel y Rodríguez, 2011).

Constatan, asimismo, "un mayor peso de los padres trabajadores manuales entre los estudiantes que trabajan más de 15 horas a la semana", y "una clara asociación entre los estudiantes que trabajan más de 15 horas y los que tienen progenitores con bajo nivel de estudios".

\section{Diferencias por sexos}

Al analizar la igualdad de oportunidades en el acceso a las titulaciones universitarias, es necesario considerar también la cuestión desde el punto de vista de la igualdad de género.

En este sentido, al igual que lo ocurrido con los factores socioeconómicos y socioculturales, se ha producido un cambio progresivo en las últimas décadas, que han visto un incremento substancial de la presencia de mujeres en la universidad, hasta el punto que, tal como muestra el Gráfico 9, hoy las mujeres representan casi el 55\% del estudiantado universitario. 


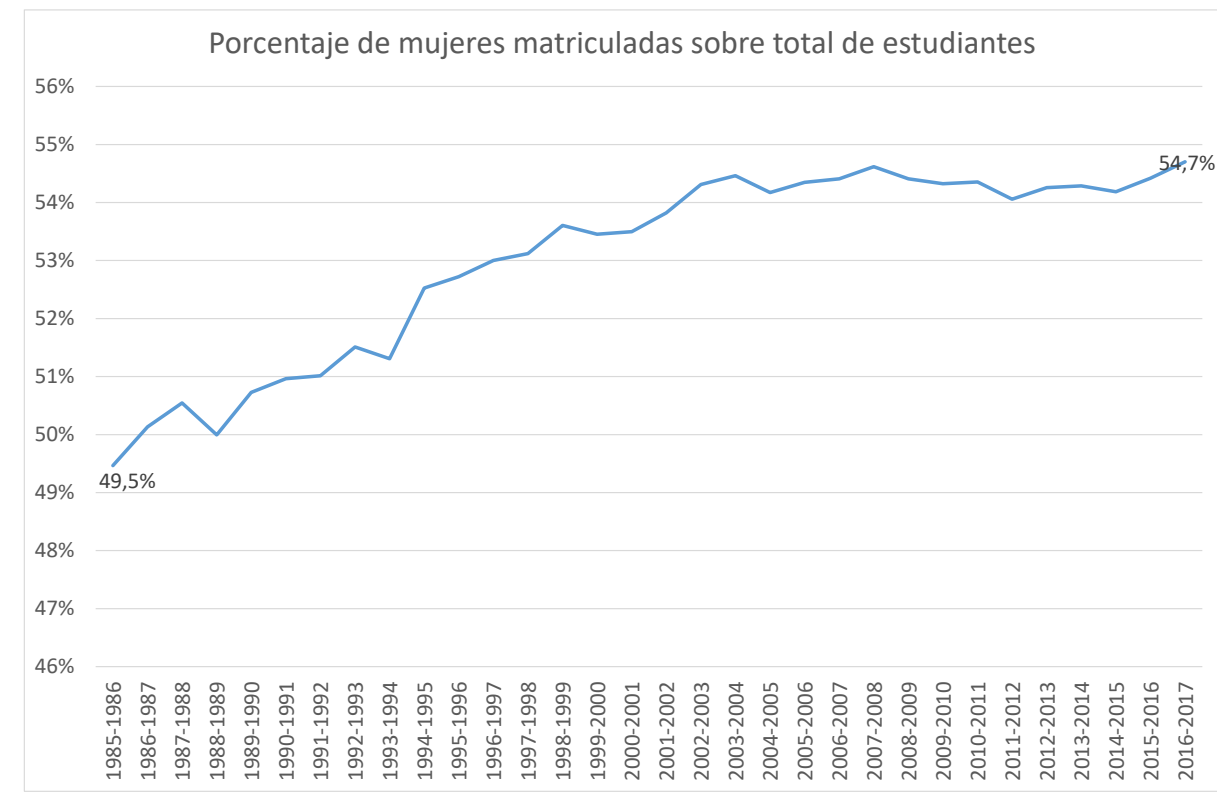

Gráfico 9. Fuente: elaboración propia a partir de MECyD (2017a).

Este porcentaje varía según el nivel de los estudios universitarios de que se trate (grado, máster o doctorado): a niveles más altos, la proporción de mujeres disminuye, aunque se mantiene en todos los casos por encima de la proporción de mujeres de la población de 18 a 24 años de edad, tal como ilustra el Gráfico 10.

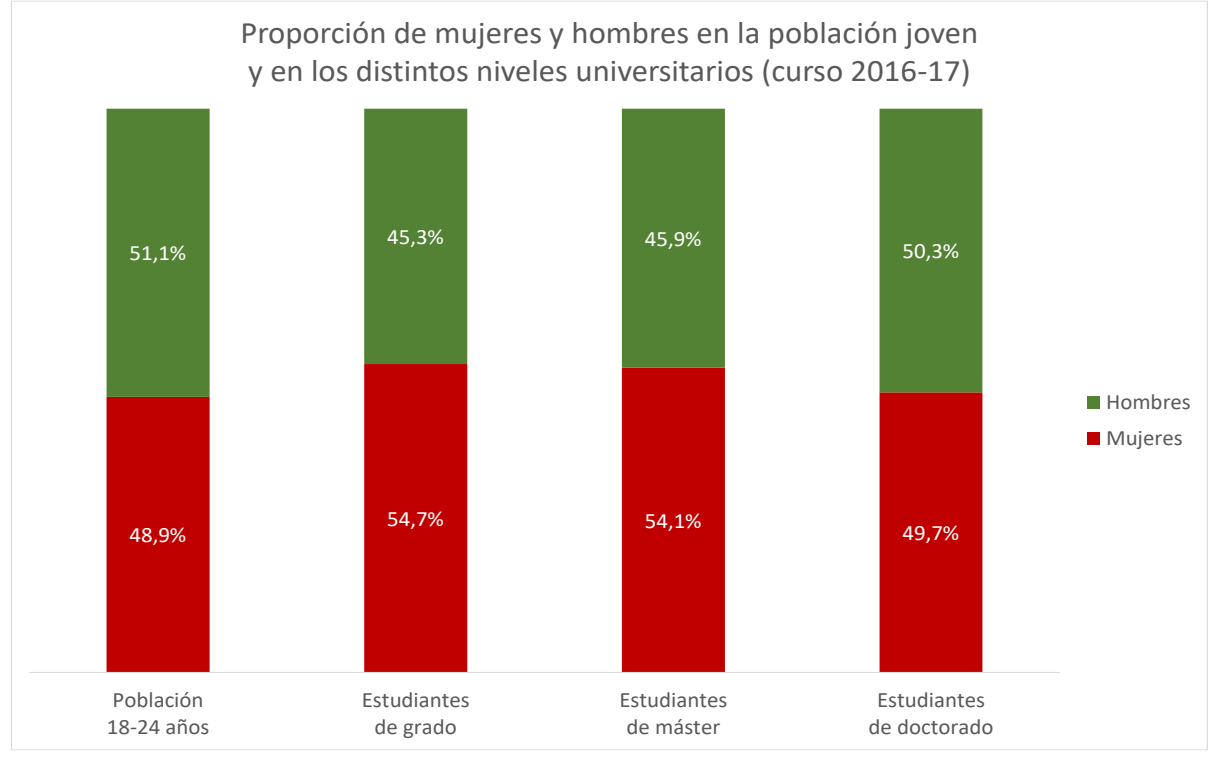

Gráfico 10. Fuente: elaboración propia a partir de INE (2017a) y MECD (2017a).

En relación con la nota de acceso a la universidad, el Gráfico 11 muestra que las notas de las mujeres son algo más altas que las de los hombres. 


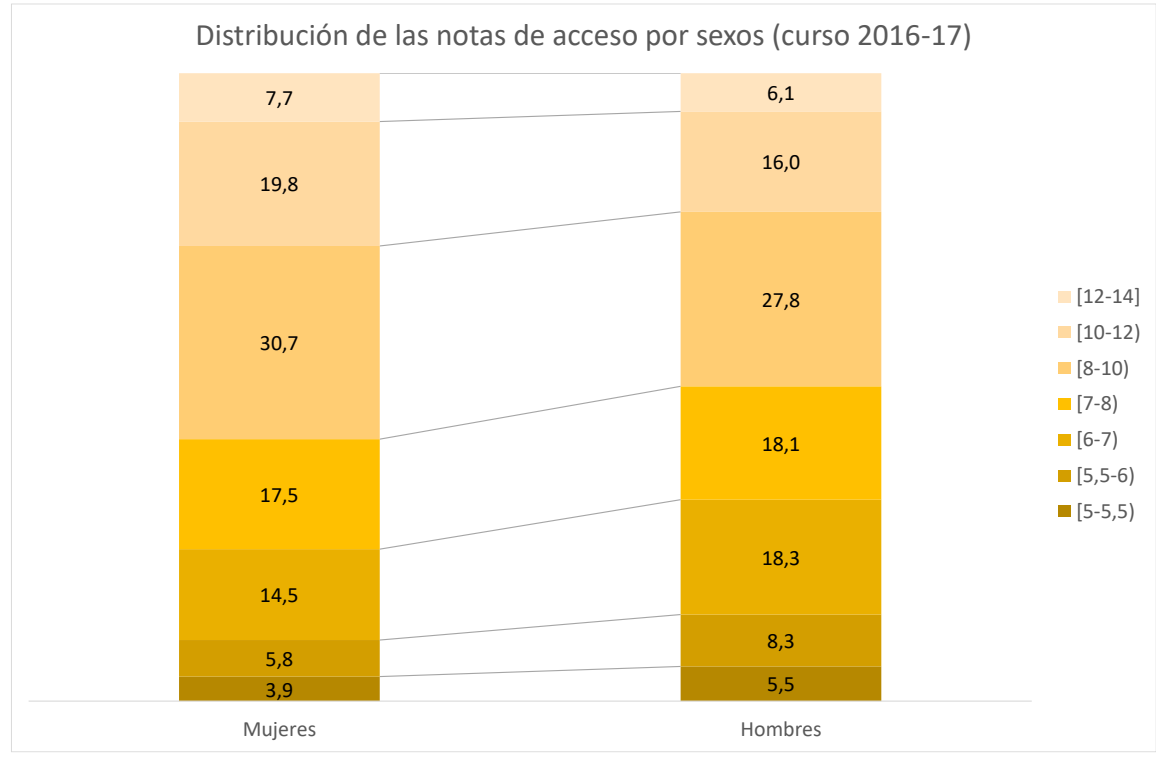

Gráfico 11. Fuente: elaboración propia a partir de MECyD (2016b).

Asimismo, se sabe que el origen social de las estudiantes universitarias es algo inferior al de sus compañeros varones: el porcentaje de progenitores trabajadores manuales es superior entre las mujeres que entre los varones (Barañano, Finkel y Rodríguez, 2011).

Todo ello podría indicar que las mujeres de clases más desfavorecidas deben demostrar más su valía para alcanzar estudios universitarios, y explicaría -en términos socioeconómicos- por qué la participación de las mujeres decrece conforme sube de nivel de estudios universitarios.

Por otro lado, los datos indican que las mujeres universitarias son en general más jóvenes que sus compañeros varones. El Gráfico 12 muestra las distribuciones de mujeres y hombres por grupos de edad, y permite constatar que las diferencias son significativas. La explicación la encontramos principalmente en el hecho de que los varones son más propensos a reengancharse a los estudios a una edad tardía (Soler, 2011).

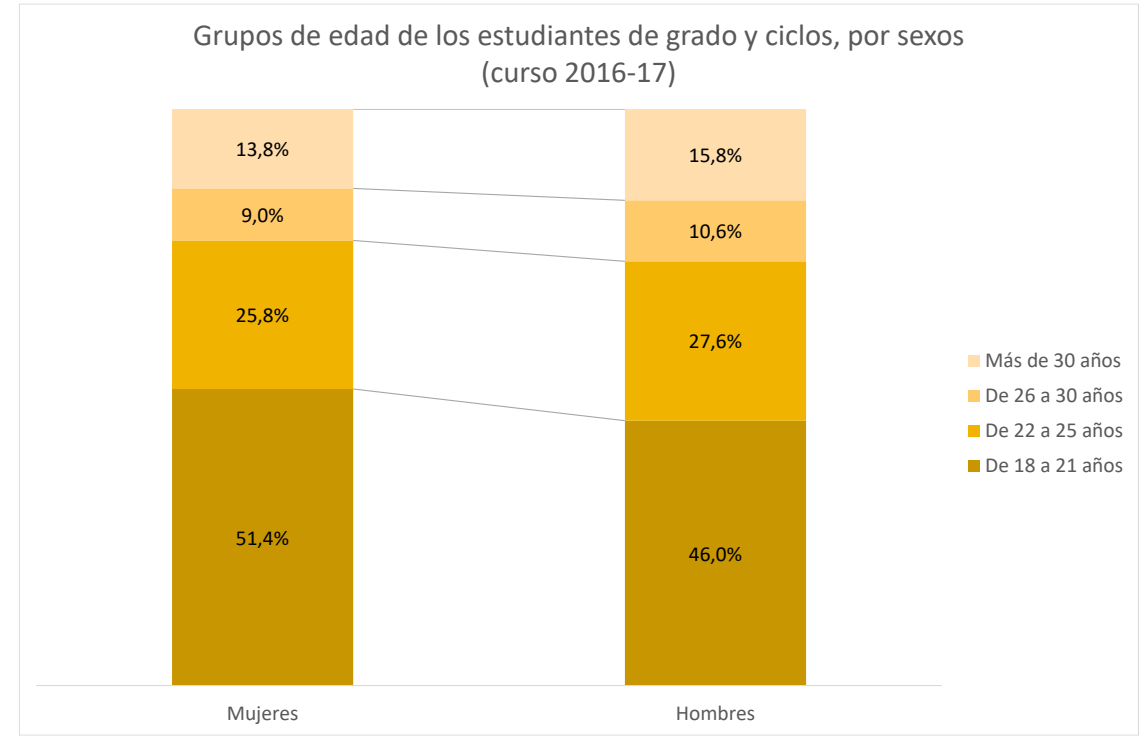

Gráfico 12. Fuente: elaboración propia a partir de MECyD (2017a). 
Al indagar en la relación con el trabajo y el estudio también se constatan diferencias significativas entre sexos, que son coherentes con los datos anteriores. Concretamente, de nuevo Soler (2011) observa que las mujeres dedican más de 40 horas semanales al estudio, con una diferencia de diez puntos porcentuales con los varones. Están por encima en cualquiera de las edades, pero especialmente entre la categorías de menor edad. Asimismo, las mujeres dedican menos horas al trabajo: ellas están sobrerrepresentadas entre los estudiantes que trabajan menos de 15 horas, ellos lo están entre los que trabajan más de 15 horas. En este respecto, los datos de España son opuestos a los del conjunto de Europa, donde son las mujeres las que más estudian a tiempo parcial.

La interpretación de Soler (2011) es que son los varones quienes compaginan en mayor medida los estudios con el trabajo o la familia y, por tanto, tienen una intensidad más baja en sus estudios, mientras que las mujeres, que conforman sus propias familias a edades más tempranas, siguen jugando en el hogar un papel más importante que ellos, con las tareas y cuidados domésticos, hecho que les impide compaginar esas actividades con el estudio y reengancharse a la universidad como estudiantes maduras.

Pero quizás las diferencias más relevantes entre estudiantes varones y mujeres radica en la elección de la carrera que cursan. Las preferencias según sexo son muy importantes en algunos ámbitos de estudio, tal como puede constatarse en el Gráfico 13.

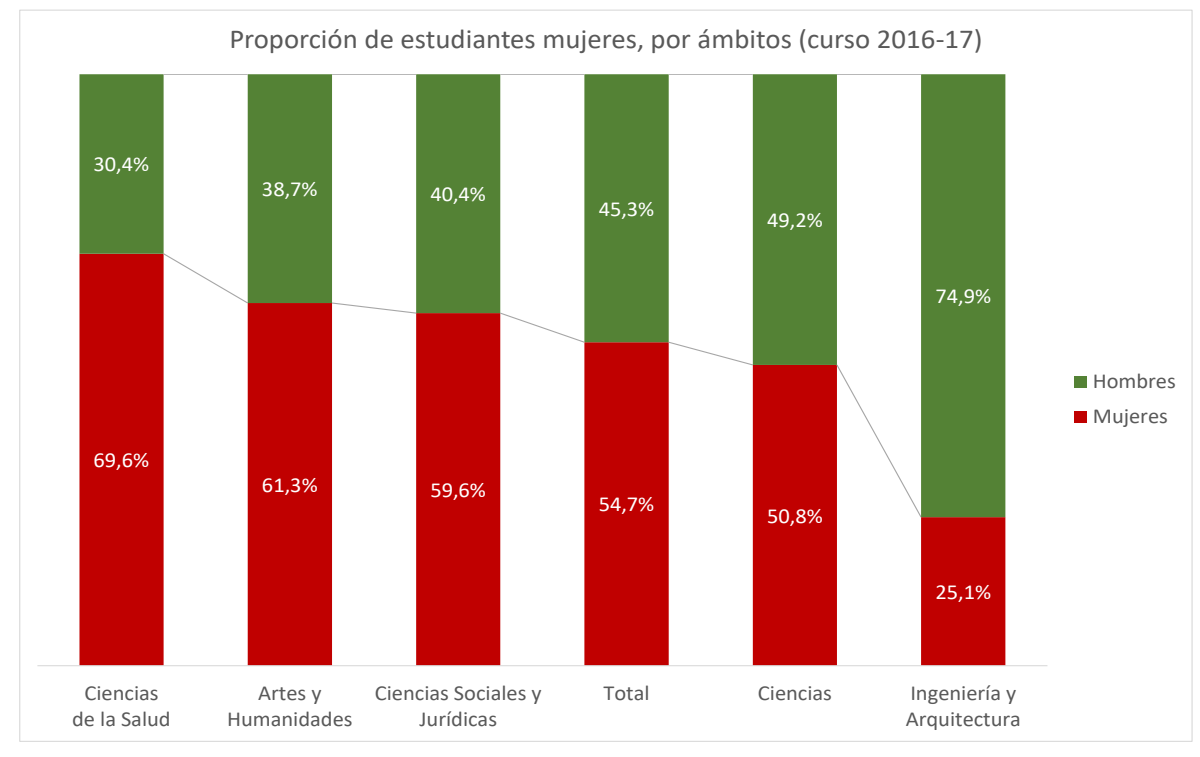

Gráfico 13. Fuente: elaboración propia a partir de MECyD (2017a).

En el extremo más feminizado, se encuentran los estudios del ámbito de las ciencias de la salud, con un $69,6 \%$ de mujeres estudiantes, seguidos de los estudios de humanidades, con un $61,3 \%$ y las ciencias jurídicas y sociales, con un 59,6\%. Algo por debajo de la media se sitúan los estudios de ciencias, con un $50,8 \%$ de estudiantes mujeres. Pero lo que resulta más preocupante es que tan sólo un $25,1 \%$ de los estudiantes de ingeniería y arquitectura son mujeres. Y más aún si se tiene en cuenta que los estudiantes de arquitectura y urbanismo se dividen por mitad entre hombre y mujeres. 
Un análisis más pormenorizado de la distribución en las distintas titulaciones mueve realmente a la reflexión. ¡El porcentaje de estudiantes mujeres es del 92,9\% en educación infantil, y del 90,8\% en logopedia, mientras en ingeniería del automóvil es del 7,4\%, y en ingeniería de computadores, del 10,3\%! El país entero debería estar preguntándose qué hacer para conseguir una sociedad con menor división de roles por sexos.

\section{Las pruebas de acceso a la universidad como garantía de equidad}

Desde su implantación el curso 1974-75, las pruebas de acceso a la universidad (PAU) han sufrido la contestación del movimiento estudiantil, que las percibe como una traba al derecho a la educación. Sin embargo, las pruebas han persistido hasta hoy, aunque con modificaciones sucesivas, las últimas de las cuales han tenido lugar en 2010 y en 2017.

Por otro lado, en estas pruebas, dirigidas a estudiantes que provienen de estudios de secundaria, las tasas de estudiantes aprobados sobre matriculados son sistemáticamente muy altas (93,82\% en la convocatoria ordinaria de 2016, por ejemplo). Incluso en las pruebas extraordinarias, que se realizan en el mes de septiembre, se obtienen tasas de estudiantes aprobados altas $(78,79 \%$ en 2016). Mención aparte debe hacerse de las pruebas de acceso para mayores de 25 años (54,08\%), mayores de 45 años (50,70\%), con porcentajes de éxito claramente inferiores, y de las pruebas de acceso para mayores de 40 años con experiencia laboral $(74,70 \%)$, con tasas de éxito más parecidas a las primeras.

Cabe preguntarse, pues, por qué, a lo largo de más de cuarenta años, gobiernos de distintos colores, con mayorías parlamentarias relativas y absolutas, han mantenido estas pruebas. De hecho, la última reforma parcial de 2017 es el resultado, probablemente provisional, de una propuesta de substitución de las pruebas de acceso a la universidad por una reválida de bachillerato que ha sido muy contestada social y políticamente. Sin embargo, a lo largo de la discusión que ha llevado a la solución de compromiso actualmente vigente, ningún partido político ni grupo parlamentario ha propuesto la eliminación de cualquier tipo de prueba para acceder a la universidad.

La explicación de este "consenso de fondo" depende, a mi entender, de diversos factores. En primer lugar, naturalmente, está la necesidad de distribuir a los estudiantes entre las distintas carreras. En otras palabras, lo realmente relevante de las pruebas de acceso a la universidad no radica en aprobarlas o suspenderlas, sino en la nota obtenida, que permite o impide el acceso a los estudios más demandados.

Pero existen otros elementos que explican por qué el sistema de distribución de estudiantes entre carreras se basa (al menos, en parte) en un examen común y no sólo en las notas que los estudiantes obtienen en sus centros de enseñanza secundaria.

Por un lado, la existencia de una prueba común determina, indirectamente, los temarios y el trabajo del profesorado de los centros de bachillerato, que fijan como meta que sus estudiantes sean capaces de aprobar los exámenes de acceso a la universidad. Por consiguiente, uno de los efectos de las PAU sería el mantenimiento de cierta homogeneidad en el nivel de conocimientos de los egresados de la enseñanza secundaria post-obligatoria.

Por otra parte, la convicción de que una prueba única, igual para todos, es más "justa". En otras palabras, una cierta desconfianza respecto de los centros docentes de secundaria que, para 
aumentar su prestigio, pudieran "hinchar" las notas de sus estudiantes, y mucha fe en que un examen común favorece la meritocracia.

Este último extremo merece una reflexión. ¿Hasta qué punto la meritocracia, aun siendo, muy probablemente, el mejor criterio de que dispone un país para promover a sus jóvenes y permitirles acceder a los estudios superiores, es aún un criterio socialmente sesgado?

Al igual que existen diferencias de clase en las elecciones educativas, relacionadas con el coste, los beneficios, la duración de los estudios o las probabilidades de éxito, también existen fuertes diferencias de clase en los resultados académicos de los estudiantes, tanto si se miden por las notas obtenidas en los distintos cursos como si se miden a través de los test y pruebas normalizadas al uso. Numerosos autores han demostrado esta relación tanto a nivel internacional como para el caso de España. En particular, en España es manifiesto que la nota de acceso sube conforme aumenta el origen social del estudiante $y$, muy particularmente, el nivel de estudios de su madre.

Últimamente, se ha propuesto que se transfiera el sistema de selección de estudiantes a las facultades y escuelas técnicas de la universidad. De hecho, la última reforma educativa iba en esta línea, al proponer una reválida de bachillerato y un acceso a la universidad no unificado, dependiente de cada universidad. La propuesta legislativa ha sido reconducida parcial y temporalmente, a falta de mayoría parlamentaria que la sostenga. Sin embargo sigue presente, y a ella se añaden las voces que abogan por una selección que no se base en conocimientos sino en aptitudes y actitudes. Esto se vehicularía no ya a través de un examen sino a través de una entrevista personal, siguiendo el modelo anglosajón. Esta forma de selección, sin embargo, favorece el sesgo de clase y refuerza claramente la desventaja de partida de los estudiantes de origen social y cultural más bajo, tal como se ha venido observando tanto en el ámbito laboral como en el de la enseñanza (Troiano, 2016).

\section{Los precios como elemento disuasorio}

De todos es conocido que en la última década se ha producido en España un incremento sustancial de los precios de las matrículas universitarias. El Gráfico 14 muestra cómo ha evolucionado el intervalo de precios de los estudios de grado desde su implantación.

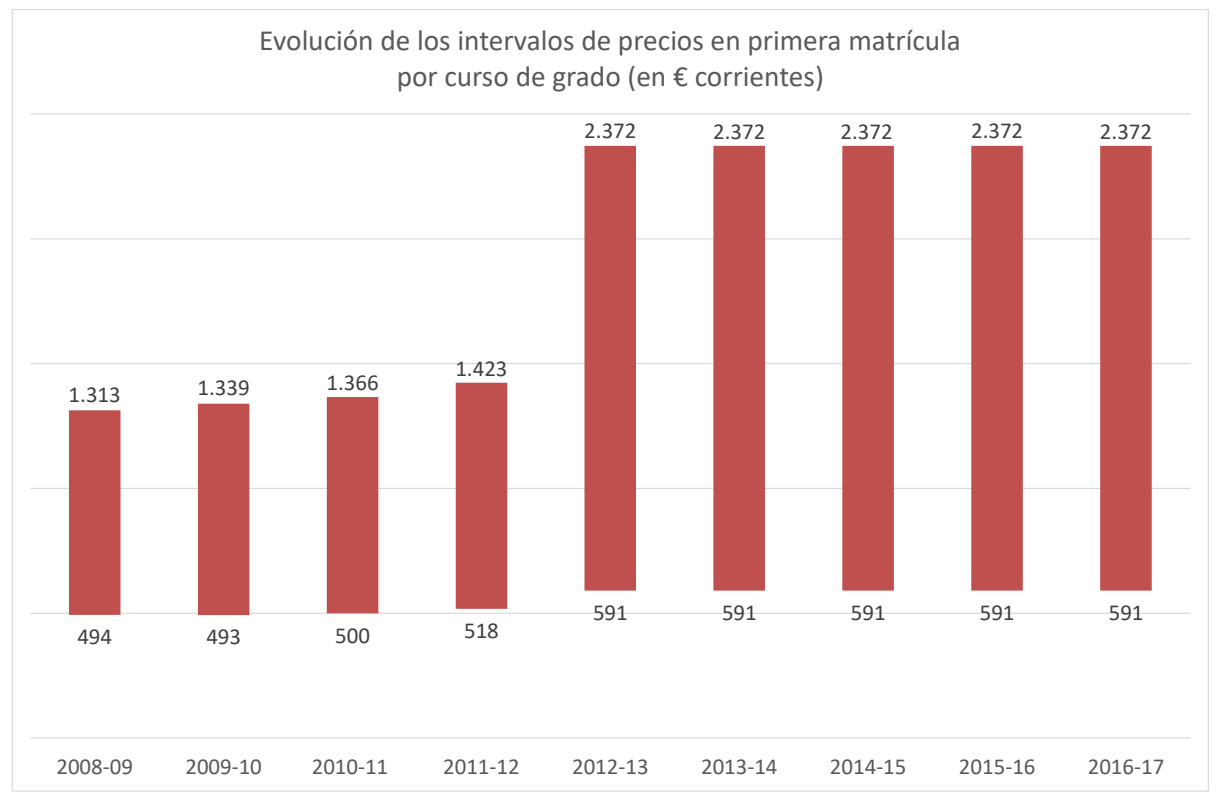

Gráfico 14. Fuente: elaboración propia a partir de MECyD (2017b) 
Quizás sea menos conocido el resultado del efecto combinado del incremento de precios de matrícula (no sólo en primera matrícula, sino también en las matrículas sucesivas), el incremento de las tasas administrativas (por gestión del expediente, por expedición de título, etc.), la modificación de la duración de los estudios (por la implantación de grados de 4 años de duración) y la modificación de la clasificación de algunas carreras según su "grado de experimentalidad", concepto éste que no se haya definido, ni mucho menos calculado, en ninguno de los decretos de precios anuales de las distintas comunidades autónomas y, sin embargo, determina los precios de las distintos estudios. Según un estudio del Observatorio del Sistema Universitario (OSU, 2013), en Cataluña la adaptación al Espacio Europeo de Enseñanza Superior ha ido acompañada de un incremento del precio total de las carreras de entre el $70 \%$ y el $290 \%$, y son mayoría las carreras cuyo precio se ha multiplicado por 2 o más.

Mención explícita debe hacerse a los estudios de máster universitario, que en España son más caros que los de grado (hasta 7 veces), lo cual constituye una anomalía en el contexto europeo.

En este sentido, conviene llamar también la atención (véase el Gráfico 15) sobre un hecho en general poco conocido, y es que la gratuidad de los estudios universitarios no es en Europa una excepción localizada tan sólo en los países nórdicos, sino la norma de una proporción muy grande de países: en el $40 \%$ de ellos o bien el estudiante no paga nada, o bien se limita a pagar unas tasas administrativas fijas que no alcanzan los $200 €$ anuales. Es más, en el $47 \%$ de los países europeos, el precio máximo de un curso de grado es inferior al precio mínimo en España.

Precio de un curso de grado y porcentaje de estudiantes que lo paga (curso 2015/16)

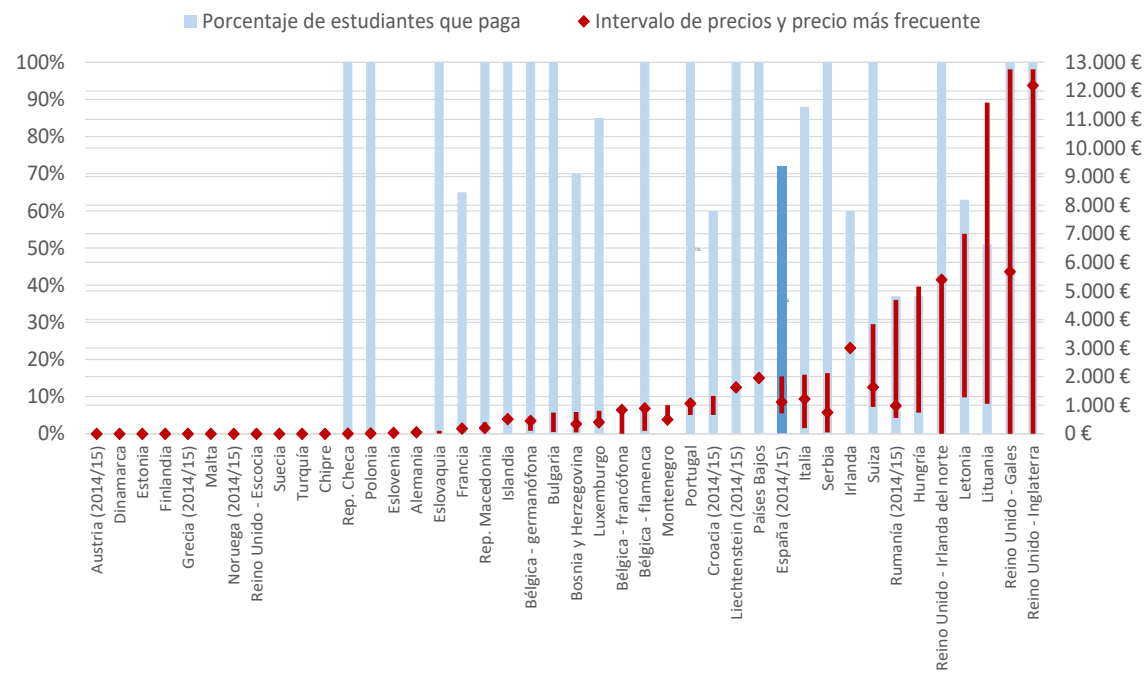

Gráfico 15. Fuente: elaboración propia a partir de Eurydice (2015).

En resumen, la estructura de precios actual, amén de ser muy desigual por comunidades autónomas (véase OSU, 2016), sitúa a nuestro país en el tercil de precios más altos de Europa y castiga económicamente tanto los estudios más avanzados (máster universitario) como la repetición de asignaturas. En un contexto en el que subsisten desigualdades sociales, tal como hemos visto en los apartados anteriores, el efecto de los precios no puede por menos que ser un elemento disuasorio más para los estudiantes económica, social y culturalmente más desfavorecidos. 


\section{Ayudas al estudio}

Aunque los precios constituyen un problema añadido para la equidad en el acceso a los estudios universitarios, probablemente el problema principal, desde un punto de vista estrictamente económico, lo constituye el coste de oportunidad, esto es, los ingresos no percibidos por la persona joven que opta por estudiar en vez de trabajar. Prueba de ello es el estancamiento de la tasa de escolarización universitaria durante el último período de boom económico, coincidiendo con un coste de oportunidad relativamente alto, y su abrupto crecimiento a partir del inicio de la última crisis financiera, coincidiendo con unas tasas de paro juvenil muy altas $y$, en otras palabras, un coste de oportunidad relativamente bajo.

Así, pues, para las personas de clase trabajadora, que ven los estudios como un privilegio y una carga para sus familias, y cuya motivación principal para estudiar en la universidad es mejorar su situación económica, el papel de las ayudas al estudio es fundamental. En este sentido, la situación en España dista mucho de ser ideal.

\subsection{Inexistencia de becas-salario}

En primer lugar, nuestro sistema universitario carece de becas-salario, que sin embargo existen en otros países europeos precisamente para compensar a los jóvenes que en vez de ponerse a trabajar optan por seguir estudiando. Los países más proclives a establecer sistemas de becassalario (véase el Gráfico 16) son aquellos en los que se tiene la concepción de la persona joven como adulta y autónoma.

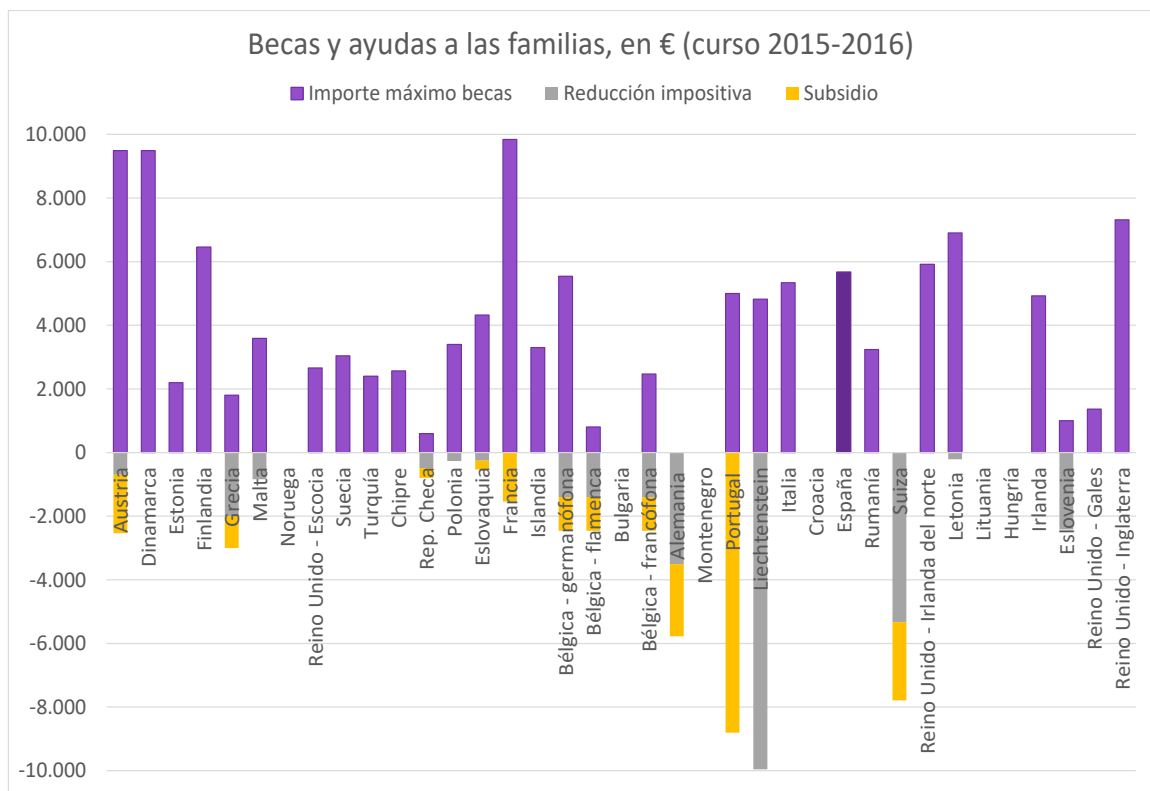

Gráfico 16. Fuente: elaboración propia a partir de Eurydice (2015).

\subsection{Inexistencia de reducciones fiscales y subsidios}

En los países en los que los jóvenes suelen vivir con sus familias más años $-\mathrm{y}$, particularmente, mientras estudian- las ayudas económicas directas al estudio no se suelen materializar tanto en becas-salario al estudiante, cuanto en desgravaciones fiscales a las familias con hijos 
universitarios, e incluso en subsidios para las familias más necesitadas cuyos hijos estudian en la universidad. Nada de todo ello existe en España.

\subsection{Becas parciales}

El sistema de becas para estudios universitarios en España tan sólo contempla los gastos de matrícula, una cantidad fija para compensar las necesidades de residencia fuera del domicilio familiar (1.500€ anuales el curso 2016-17), y una cuantía variable en función del nivel de renta familiar. Las becas, cuyo importe medio anual el curso 2014-15 fue de 2.440€, alcanzaron al 23,8\% del estudiantado universitario (MECyD, 2016b). Además, hay que tener en cuenta que una parte del importe de estas becas es variable y depende, entre otras cosas, de las notas obtenidas y del número de becas concedidas, lo cual genera incertidumbre entre el estudiantado que las necesita para poder seguir estudiando y no puede saber a priori con cuánto dinero contará si obtiene la beca.

\subsection{Requisitos académicos añadidos para la obtención de becas}

La mayor exigencia académica para la obtención y renovación de becas, implantada en España a partir de 2012, añade un elemento de incertidumbre más a nuestro sistema de becas, que pasa a exigir mejores resultados académicos a quienes padecen más necesidades económicas. Esto comporta, además, requerir expedientes académicos mejores a las clases trabajadoras, que entran en la universidad, como sabemos, con notas más bajas. Todo indica que estos requisitos reforzarán la tendencia de los estudiantes de clases trabajadoras a recurrir a estrategias reductoras del riesgo. En particular, se ha constatado una caída en el número de créditos que los estudiantes matriculan por curso (França, 2014) atribuible, con toda probabilidad, a la combinación entre el aumento de precio de las matrículas sucesivas a la primera y la aparición de requisitos académicos suplementarios para la obtención y renovación de las becas.

\section{5 ¿Becas o préstamos?}

En los últimos años, diversas voces se han manifestado a favor de substituir las becas al estudio por préstamos. Hasta el punto de que en 2014 el entonces ministro de Educación, Cultura y Deporte, y su secretaria de Estado de Educación, Formación Profesional y Universidades (hoy embajador representante permanente de España ante $O C D E$, y directora adjunta de la Dirección de Educación de la OCDE, respectivamente) formularon esta propuesta, que no prosperó. La experiencia de los países en que se hace un mayor uso de préstamos en lugar de becas básicamente Estados Unidos e Inglaterra- ha puesto de manifiesto que dicho sistema presenta gravísimos inconvenientes. Para empezar, es socialmente injusto, al lanzar a los titulados al mercado de trabajo en condiciones muy distintas de endeudamiento, dependiendo de su situación socioeconómica de partida, haciendo a los económicamente más desfavorecidos aún más vulnerables a la hora de elegir entre opciones de trabajo, y condicionando aún más sus opciones de vida personal y familiar. Por otro lado, es bien conocido, por haber aparecido en los medios de comunicación de forma recurrente, que los sistemas basados en préstamos universitarios acaban causando problemas financieros a la economía, pues generan burbujas de crédito insostenibles. En un país como España, que cuenta con preocupantes niveles de deuda 
privada causada por las dificultades de acceso a la vivienda, sería claramente contraproducente añadir a los jóvenes una nueva deuda, motivada por sus estudios.

\subsection{Ayudas indirectas prácticamente irrelevantes}

El alojamiento es uno de los costes principales asociados al estudio. En España, a diferencia de muchos países europeos, las residencias universitarias son pocas, mayoritariamente de propiedad privada y con precios no subvencionados. Así, una gran mayoría de los estudiantes universitarios vive con sus padres o, en ocasiones, en un piso compartido cuyo alquiler puede comportar un coste de hasta $600 €$ al mes. Tampoco existen, de forma generalizada, tarifas de transporte público gratuitas para estudiantes $-\mathrm{O}$, al menos, reducidas-, como en cambio se encuentran con frecuencia en toda Europa. Y finalmente, han ido desapareciendo los comedores universitarios a precios subvencionados que, sin embargo, persisten en muchas universidades europeas, en las que un menú más que digno puede costar entre $1 €$ y $5 €$.

La práctica ausencia de este tipo de ayudas indirectas al estudio en España dificulta ulteriormente no sólo el acceso de las clases populares al estudio, sino incluso la movilidad de los estudiantes de clase media, que se matriculan en universidades cercanas geográficamente al domicilio de sus familias para minimizar los costes añadidos de alojamiento, transporte o alimentación, en detrimento de una elección más vocacional de la universidad en la que estudiar.

\section{A modo de conclusión: equidad y aprovechamiento del talento}

Todo lo descrito hasta aquí configura un sistema universitario que ha evolucionado progresivamente hacia una configuración más amplia y equitativa, pero en el que subsisten desigualdades manifiestas de índole económica, sociocultural y por sexo. Esto por sí mismo debería inquietar a toda la ciudadanía y a nuestros gobernantes, aunque sólo fuera por motivos de equidad.

Sin embargo, no sólo de equidad se trata. Las desigualdades en el sistema educativo en general, $y$ en el universitario en particular, comportan un mal aprovechamiento del talento de una sociedad. Que una persona joven decida seguir estudios universitarios (o no hacerlo), o estudiar una carrera u otra, en función, entre otros factores, de su extracción sociocultural, su capacidad económica y la de su familia, o de su sexo, en vez de hacerlo estrictamente en función de su capacidad y su interés, es contraproducente para un país que quiera obtener el máximo rendimiento posible de sus jóvenes, y totalmente contradictorio con las reiteradas declaraciones de nuestros gobernantes sobre la necesidad de adaptar Europa y, con ella España, a la sociedad del conocimiento.

A medida que se moderniza un país, su nivel educativo aumenta, y viceversa: para que el país se pueda seguir modernizando, se requiere que proporciones cada vez más altas de la población accedan a la universidad, y que lo hagan quienes más partido pueden sacar de ella, por su capacidad y por su voluntad de aprender. Por consiguiente, es importante trabajar para reducir las inequidades no sólo por motivos de justicia social (como si esto no fuera, de por sí, motivo más que suficiente) sino también por interés colectivo. Una universidad socialmente más justa beneficia no sólo a quiénes acceden a ella, sino también al resto de la población, que se beneficia de los tan pregonados "desarrollo e innovación" que sus titulados llevan a cabo una vez se insieren en el tejido económico del país. 
Para ello, y según hemos visto a lo largo de este texto, se necesita democratizar el acceso a la universidad a través de su gratuidad $\mathrm{o}$, al menos, mediante una reducción substancial y sostenida de los precios de matrícula, que nos equipare a países como Francia (184€ por curso), Austria (matrícula gratuita) o Alemania (entre $0 €$ y $75 €$ por curso), por referirnos tan sólo a tres países de nuestro entorno más cercano. Mediante la introducción de becas salario, que permitan compensar el coste de oportunidad, y, más en general, un sistema de becas estable y suficiente. Mediante la implantación de desgravaciones fiscales y subsidios a las familias como existen en Francia, Austria o Alemania, por seguir con los ejemplos anteriores. Invirtiendo en ayudas indirectas al estudio a través de comedores universitarios, precios subvencionados de transporte público y residencias universitarias a precios accesibles. Y eliminando la penalización económica al bajo rendimiento académico, y dando a éste un tratamiento equitativo para todos. En fin, trabajando a lo largo y ancho de toda la sociedad para reducir las diferencias sociales de rendimiento académico y los patrones sexistas relativos a las ocupaciones profesionales.

\section{Referencias bibliográficas}

Arcas, O. y Sacristán, V. (2014). L'accés a la universitat. En AAVV, En els 25 anys d'UnC: Materials per fomentar el futur de la universitat pública (pp. 45-50), Barcelona, U(pi)C - Associació per al Debat i la Reflexió a la UPC.

Barañano, M.; Finkel, L. y Rodríguez, E. (2011). Procedencia sociofamiliar. En Ariño, A. y Llopis, R. (Editores). ¿Universidad sin clases? Condiciones de vida de los estudiantes universitarios en España (Eurostudent IV), Ministerio de Educación, Recuperado de https://sede.educacion.gob.es/publiventa/universidad-sin-clases-condiciones-de-vida-de-losestudiantes-universitarios-en-espana-eurostudent-iv/universidad-espana/14909

Bernardi, F. y Cebolla, H. (2014). Clase social de origen y rendimiento escolar como predictores de las trayectorias educativas. Revsita Española de Investigaciones Sociológicas 146:3-22. doi: 10.5477/cis/reis.146.3.

Bernardi, F. y Requena, M. (2007). Expansión del sistema educativo y reducción de la desigualdad de oportunidades en España, Panorama Social, 6. Recuperado de http://www.funcas.es/publicaciones_new/Sumario.aspx?ldRef=4-15006

Bernardi, F. y Requena, M. (2010). Desigualdad y puntos de inflexión educativos: el caso de la educación post-obligatoria en España. Revista de Educación, número extraordinario. Recuperado de http://www.revistaeducacion.mec.es/re2010_04.htm

Calero, J. y Choi, A. (2012). El efecto de las desigualdades socioeconómicas en el sistema educativo español, Ekonomiaz, 81. Recuperado de http://www.euskadi.eus/web01a2reveko/es/k86aEkonomiazWar/ekonomiaz/abrirArticulo?idpubl=77\&registro=1230

Eurydice (2015). European Commission/EACEA/Eurydice, National Student Fee and Support Systems in European Higher Education - 2015/16. Eurydice Facts and Figures. Luxembourg: Publications Office of the European Union. Recuperado de http://eacea.ec.europa.eu/education/eurydice/img/covers/189EN.pdf

Eurostat (2016). Unemployment rates of the population aged 25-64 by educational attainment level. Recuperado de http://ec.europa.eu/eurostat/data/database 
França, J. (2014). L'equitat del sistema universitari, en entredit. El Diari de l'Educació. Recuperado de http://diarieducacio.cat/equitat-del-sistema-universitari-en-entredit/

INE (2017a). Instituto Nacional de Estadística, Población residente por fecha, sexo y edad. Recuperado de http://www.ine.es/jaxiT3/Tabla.htm?t=10256

INE (2017b). Instituto Nacional de Estadística, Encuesta de población activa: Población de 16 y más años por nivel de formación alcanzado, sexo y grupo de edad. Recuperado de http://www.ine.es/jaxiT3/Tabla.htm?t=6347

INE (2017c). Instituto Nacional de Estadística, Encuesta de Población activa: Serie 2002-2013. Recuperado de http://www.ine.es/dynt3/inebase/es/index.htm?padre=1004

MECyD (2017a). Ministerio de Educación, Cultura y Deporte, Estadística de estudiantes. Curso 2016-17. Recuperado de http://www.mecd.gob.es/servicios-al-ciudadanomecd/estadisticas/educacion/universitaria/estadisticas/alumnado.html

MECyD (2017b). Ministerio de Educación, Cultura y Deporte, Estadística de precios públicos universitarios. Recuperado de http://www.mecd.gob.es/servicios-al-ciudadanomecd/estadisticas/educacion/universitaria/estadisticas/precios-publicos.html

MECyD (2016a). Ministerio de Educación, Cultura y Deporte, Estadística de las pruebas de acceso a la universidad. Año 2016. Recuperado de http://www.mecd.gob.es/servicios-al-ciudadanomecd/estadisticas/educacion/universitaria/estadisticas/estadistica-de-las-pruebas-de-acceso-ala-universidad0.html

MECyD (2016b). Ministerio de Educación, Cultura y Deporte, Anuario de indicadores universitarios. Recuperado de http://www.mecd.gob.es/servicios-al-ciudadanomecd/estadisticas/educacion/universitaria/estadisticas/estadistica-indicadoresuniversitarios/2016-2017.html

MECyD (2016c). Ministerio de Educación, Cultura y Deporte, Nivel de formación de la población. Recuperado de http://www.mecd.gob.es/servicios-al-ciudadanomecd/estadisticas/educacion/mercado-laboral/epa2016.html

Micó, J. y Zapata, V. (2016). Dades sociodemogràfiques. En E. Sintes (coord.), Via Universitària: Ser estudiant universitari avui (pp. 201-220). Barcelona, Fundació Jaume Bofill. Recuperado en www.fbofill.cat/sites/default/files/ViaUniversitaria_doctreball_010616.pdf

OCDE (2015). Organización para la Cooperación y el Desarrollo. Unemployment rates by education level. Recuperado de https://data.oecd.org/unemp/unemployment-rates-by-education-level.htm

OSU (2016). Observatorio del Sistema Universitario. ¿Por qué precios tan distintos? Precios y tasas en las universidades públicas en España, curso 2016/17. Recuperado de http://www.observatoriuniversitari.org/es/2017/01/25/por-que-precios-tan-distintos/

OSU (2014). Observatorio del Sistema Universitario. El coste de estudiar en Europa. Precios, becas, préstamos y otras ayudas en las universidades europeas (2013-14). Recuperado de http://www.observatoriuniversitari.org/es/2014/06/19/el-coste-de-estudiar-en-europa/

OSU (2013). Observatorio del Sistema Universitario. El precio de la carrera. Precios universitarios 2013-14 en Cataluña y análisis de la evolución del precio total de los estudios. Recuperado de http://www.observatoriuniversitari.org/es/2013/07/22/el-precio-de-la-carrera/ 
Pérez Díaz, V. y Rodríguez, J.C. (2001). Educación superior y futuro de España, Fundación Santillana.

Requena, M. (2016). El ascensor social. ¿Hasta qué punto una mejor educación garantiza una mejor posición social?, Observatorio Social de La Caixa, Recuperado de https://observatoriosociallacaixa.org/es/article/-/asset_publisher/ATai9MyKZiYq/content/elascensor-social-hasta-que-punto-una-mejor-educacion-garantiza-una-mejor-posicion-social-

Soler, I. (2011). Características sociodemográficas. En Ariño, A. y Llopis, R. (Editores). ¿Universidad sin clases? Condiciones de vida de los estudiantes universitarios en España (Eurostudent IV), Ministerio de Educación, Recuperado de https://sede.educacion.gob.es/publiventa/universidadsin-clases-condiciones-de-vida-de-los-estudiantes-universitarios-en-espana-eurostudentiv/universidad-espana/14909

Troiano, H. (2016). Accés a la universitat. En E. Sintes (coord.), Via Universitària: Ser estudiant universitari avui (pp. 55-66). Barcelona, Fundació Jaume Bofill. Recuperado en www.fbofill.cat/sites/default/files/ViaUniversitaria_doctreball_010616.pdf

Troiano, H. y Elias, M. (2014). University access and after: explaining the social composition of degree programmes and the contrasting expectations of students, Higher Education 67:637-654. doi: $10.1007 / s 10734-013-9670-4$

Troiano, H., Torrents, D. y Sànchez-Gelabert, A. (2016). La composició social de l'accés a la universitat. En H. Troiano, S. Fachelli, J. Planas, A. Sànchez-Gelabert, M. Figueroa, M. Elias, D. Torrents y L. Daza, Equitat en l'accés $i$ en la inserció professional dels graduats universitaris. Agència per a la Qualitat del Sistema Universitari de Catalunya. Recuperado de http://www.aqu.cat/elButlleti/butlleti81/articles1.html 